\title{
A Socioeconomic Analysis of OBESITY AND INTRA-HOUSEHOLD NUTRITIONAL INEQUALITY IN INDONESIA
}

\author{
Dissertation \\ zur Erlangung des Doktorgrades \\ im Promotionsstudiengang Internationales Ph.D. Programm für \\ Agrarwissenschaften (IPAG), \\ der Fakultät für Agrarwissenschaften, \\ der Georg-August-Universität Göttingen
}

vorgelegt von

Cornelia Römling

geboren in Hamm-Heessen

Göttingen, März 2012 
D7

1. Name of supervisor: Prof. Dr. Matin Qaim

2. Name of co-supervisor: Prof. Stephan Klasen, PhD

Date of dissertation: 31. May 2012 


\section{SUMMARY}

While underweight has always been a challenge in developing countries, many poorer countries are today increasingly affected by overweight and obesity. Leading causes for this development are changes in food consumption and lifestyle patterns. Consumption patterns change from traditional diets to diets high in fats and sugar. Meat and dairy products are increasingly consumed. In addition, the availability of processed meals from newly emerging supermarkets and eating out also change diets. Moreover, other parts of life undergo transition processes with increasing income and urbanization. While work becomes more sedentary, life gets more comfortable with appliances as helping hands in households and increased motorized transportation. Leisure time is spent to a greater extent with television, internet and video games, even in poorer households. In the developed world, these aspects have been part of the normal way of life for years. This so-called nutrition transition progressively penetrates developing countries today. Developments started in Latin America, North Africa, the Middle East and Central Europe and recently even arrived in Asia and Sub-Saharan Africa.

Owing to these changes, the nutritional status of the populations improves. Sufficient calorie input is affordable for large parts of the population and energy expenditure due to lower activity burdens is not so high anymore. Accordingly, undernutrition is going down. However, there is an almost immediate increase in overweight and obesity which limits again productivity and leads to high cost noncommunicable diseases. Even worse, in most countries underweight did not completely vanish but coexists now with the new challenge of obesity. Furthermore, this dual 
burden of nutrition, evident in most developing countries, can even be found at the household level. Underweight children and overweight mothers is the most prevalent paradoxical combination in developing countries. These different nutritional outcomes challenge policy approaches even more, since selection and targeting of strategies to address overweight and obesity at the same time is complex.

With Indonesia as an example, this study sheds light on nutritional changes and nutritional inequality at the household level over time. While previous micro level studies on obesity have mostly used cross-sectional data, we analyze trends and determinants with panel data from Indonesian households. Our analysis among adults confirms that Indonesia is in the process of a fast and profound nutrition transition, with constantly rising obesity rates. The overweight problem in Indonesia is especially pronounced among females. Unlike often cited believes, rising obesity is not confined to urban and relatively richer households, but is increasingly observed in rural areas and low income segments. Panel regressions show that changes in food consumption and physical activity levels are important determinants of Body Mass Index (BMI) in Indonesia. Moreover, the results suggest an additional increase in extent and severity in the obesity pandemic in Indonesia, unless significant remedial action is taken in the near future.

In the second part of our study, we incorporate for the first time a panel data approach into research of intra-household inequality of nutrition. The categorization of households shows that 20 percent of all Indonesian households are dual burden households. While children comprise a high share of the underweight household members, female adults are often the ones with overweight. Trends over time indicate that dual burden households are households in transition that will develop to a large 
extent to overweight households in the future. Still, high vulnerability of households falling back into underweight also seems to prevail.

Our second measure, the intra-household Theil index, is newly introduced by us into this research. This continuous measure is an exact measurement of differences in nutritional outcome at the household level. We find that the Theil index increases significantly over time and is also high in overweight households. Similar to obesity, intra-household nutritional inequality becomes a problem of the poor strata over time. Furthermore, households with high inequality, measured by both the categorization as well as the Theil index, tend to share features of the nutrition transition and belong most probably to the generation of households just involved in changing consumption patterns and behavior. Panel regressions provide support for a further increase of nutritional inequality since factors positively associated with the Theil index in regression analysis will increase in the future. Female decision-making supports a more equal distribution and/or better adaption to personal needs, lowering inequality.

The results from our two empirical studies bring up important policy implications. A crucial precondition is that policymakers recognize obesity as a serious health and development issue. For this, an important starting point is the use of BMI cut-off values for Asian populations in national health and nutrition statistics as the use of international cut-offs leads to an underestimation of the obesity problem in Asia. Policy approaches need to raise awareness for the obesity problem and its costs in terms of lost health and life quality.

To improve the situation, broad-based education and information campaigns towards more balanced diets and physical exercises should be considered, also clearly explaining the health risks associated with excess weight. They need to be accompanied 
by actions promoting the different needs of children e.g., in micronutrients to reduce intra-household inequality. Women should be in the center of educational campaigns because of their high obesity levels as well as for their crucial role in intra-household distribution. Private-public partnerships may be important when it comes to measures in the food industry to reduce the usage and consumption of sugar, fat, and salt. Moreover, the improvement of the healthcare system is important to increase the monitoring of nutrition in individuals and detect reliably micronutrient deficiencies that increase inequalities at household level. 


\section{ZUSAMMENFASSUNG}

Unterernährung ist schon immer ein großes Problem in Entwicklungsländern. Heutzutage sind jedoch viele dieser ärmeren Länder zudem auch mit Übergewicht in der Bevölkerung konfrontiert. Als Hauptfaktoren für diese Entwicklung können Veränderungen der Ernährungsgewohnheiten und des Lebensstils im Allgemeinen gesehen werden. Die Ernährungsgewohnheiten ändern sich rapide: der Fett und Zuckerkonsum steigt und Fleisch und Milchprodukte stehen vermehrt auf dem Speiseplan. Außerdem verändern das steigende Angebot an Fertiggerichten durch die sich rasant in Entwicklungsländern verbreitenden Supermärkte sowie das vermehrte außer Haus essen die Essensgewohnheiten.

Desweiteren führen steigende Einkommen und die fortschreitende Urbanisierung zu einer Veränderung des Lebensumfeldes. Während Arbeitsstellen zunehmend sitzende Tätigkeiten beinhalten, wird die tägliche Haushaltsarbeit durch das vermehrte Vorhandensein von Haushaltsgeräten weniger belastend. Darüber hinaus nimmt die Bewegung im Alltag durch den Ausbau der öffentlichen Verkehrsmittel und einem vermehrten Aufkommen von Autos zu. Bei den Freizeitaktivitäten sieht man ebenfalls eine wichtige Veränderung. Fernsehen, Internet und Videospiele werden zu Hauptbeschäftigungen und tragen so zu einer starken Verminderung des Kalorienverbrauchs auch in ärmeren Bevölkerungsschichten bei.

Dieser Prozess, im Englischen „Nutrition Transition“ genannt, der neben den Veränderungen der Ernährungsgewohnheiten auch die anderen oben genannten Veränderungen des Lebensstils beinhaltet, findet zunehmend in Entwicklungsländern statt. 
Den Prozess der „Nutrition Transition“ konnte man zunächst in Lateinamerika, Nordafrika, dem mittleren Osten und Zentraleuropa beobachten und jetzt erreicht er auch Sub-Sahara Afrika und Asien.

Auf der einen Seite sind die Veränderungen der Lebensgewohnheiten mit einer Verbesserung des Gesundheits- und Ernährungszustandes verbunden. Weite Teile der Bevölkerung können sich ausreichend Nahrung leisten und der Kalorienverbrauch ist geringer durch eine weniger hohe Anstrengung in allen Lebensbereichen. Dadurch kommt es zu einer Reduzierung der Unterernährung. Fast gleichzeitig nimmt aber auch das Aufkommen von Übergewicht zu, welches zu Einschränkungen in der Produktivität und $\mathrm{zu}$ sehr kostenintensiven chronischen Krankheiten wie Herz-KreislaufErkrankungen, Bluthochdruck und Diabetes führt. Zusätzlich kann die Unterernährung meist nicht ganz ausgemerzt werden und bildet zusammen mit dem Aufkommen von Übergewichtigkeit eine doppelte Last für die finanzschwachen Entwicklungsländer. Diese doppelte Bürde ist nicht nur auf Länderebene ein Problem, sondern besteht teilweise sogar innerhalb eines Haushaltes. Die häufigste paradoxe Kombination von Unterschieden im Ernährungszustand ist die Existenz von untergewichtigen Kindern und übergewichtigen Müttern in ein und demselben Haushalt. Die Formulierung und Umsetzung politischer Strategien für dieses Problem sind eine große Herausforderung, da sowohl die Auswahl der Strategien als auch die Bestimmung der Empfänger von politischen Maßnahmen sehr komplex ist.

Unsere Studie untersucht am Beispiel von Indonesien die Veränderungen des Ernährungszustands und der Ungleichheit auf der Haushaltsebene über die Zeit. Solche Studien wurden bis jetzt meist nur mithilfe von Querschnittsdaten durchgeführt, wir dagegen haben Paneldaten, um Trends und Determinanten in indonesischen Haushalten 
zu untersuchen. Bei der Untersuchung der Erwachsenen stellen wir fest, dass sich Indonesien in einer schnellen und umfassenden „Nutrition Transition“ befindet. Die Übergewichts- und Fettleibigkeitsraten steigen beständig, wobei das Problem besonders bei den Frauen stark ausgeprägt ist. Außerdem sind nicht nur städtische und reiche Haushalte betroffen, sondern auch in ländlichen Gebieten und unteren Einkommenssegmenten sind steigende Raten $\mathrm{zu}$ finden. Die Ergebnisse der Panelregressionen zeigen, dass Veränderungen der Ernährungsweise und der körperlichen Aktivität wichtige Determinanten des Body Mass Index in Indonesien sind. Zusätzlich zeigen unsere Resultate, dass das Ausmaß und die Schwere des Problems weiter ansteigen werden, wenn nicht bald bedeutende Abhilfe geschaffen wird.

Im zweiten Teil unserer Studie benutzen wir einen Paneldatenansatz und untersuchen die Ungleichheit im Ernährungszustand innerhalb von Haushalten. Die Verwendung von Paneldaten stellt eine wichtige Neuerung in diesem Forschungsbereich dar. Die Kategorisierung von Haushalten zeigt, dass Haushalte mit untergewichtigen und übergewichtigen Mitgliedern etwa 20 Prozent aller Haushalte ausmachen. Während Kinder einen großen Teil der untergewichtigen Mitglieder stellen, sind erwachsene Frauen diejenigen, die am häufigsten übergewichtig sind. Der Trend über die Jahre zeigt, dass sich besonders die Haushalte mit sowohl unter- als auch übergewichtigen Mitgliedern in einer Umbruchphase befinden, wobei sich ein großer Anteil dieser mit der Zeit zu übergewichtigen Haushalten entwickelt. Gleichzeitig haben viele dieser Haushalte in späteren Perioden erneut mit Unterernährung zu kämpfen.

Neben der Kategorisierung von Haushalten nutzen wir ein zweites Maß, den Theil Index auf der Haushaltsebene, den wir in diesen Bereich der Forschung neu einführen. Der Index ist ein stetiges Maß und kann so exakt die Unterschiede in 
Ernährungsresultaten auf der Haushaltsebene messen. Wir finden heraus, dass der Theil Index signifikant ansteigt im Laufe der Zeit, und dass er in übergewichtigen Haushalten relativ hoch ist. Wie auch Fettleibigkeit wird Ungleichheit innerhalb des Haushalts verstärkt zu einem Problem der ärmeren Bevölkerungsschichten. Haushalte mit hoher Ungleichheit sind denjenigen Haushalten ähnlich, die sich in der „Nutrition Transition“ befinden, und zeigen veränderte Ernährungs- und Verhaltensgewohnheiten.

Unsere Panelregressionen zeigen auch hier, dass das Problem der Ungleichheit des Ernährungszustands weiter wachsen wird, da Faktoren, die mit steigender Ungleichheit verbunden sind, erwartungsgemäß auch in der Zukunft weiter zunehmen werden. Die Ergebnisse der Studie zeigen, dass eine stärkere Position der Frau im Haushalt, wie zum Beispiel als Familienvorstand, zu einer ausgeglicheneren Verteilung und einer verbesserten Anpassung an individuelle Bedürfnisse innerhalb eines Haushaltes führt, so dass die Ungleichheit verringert werden kann.

Die Ergebnisse der zwei empirischen Studien bringen wichtige politische Handlungsempfehlungen hervor. Eine wichtige Vorbedingung ist, dass politische Entscheidungsträger Fettleibigkeit als ein wichtiges Gesundheits- und Entwicklungsproblem anerkennen. Dafür ist auch die Verwendung der angepassten Klassifizierungen des BMI für asiatische Bevölkerungsgruppen ein sehr wichtiger Ansatzpunkt, um das Problem in den Ländern Asiens nicht zu unterschätzen. Politische Herangehensweisen müssen für das Problem der Fettleibigkeit sowie die damit verbundenen Gesundheitskosten und Verluste in Lebensqualität ein Bewusstsein bilden.

Großangelegte Bildungs- und Informationskampagnen, die eine ausgewogene Ernährung sowie Sport und Bewegung propagieren und die Gesundheitsrisiken, die durch Übergewicht entstehen, erklären, sollten in Betracht gezogen werden. Dabei 
müssen aber auch immer die verschiedenen Bedürfnisse einzelner Bevölkerungsgruppen, wie zum Beispiel die Wichtigkeit von Vitaminen und Mineralstoffen in der Ernährung von Kindern, hervorgehoben werden, um die Ungleichheit innerhalb des Haushaltes zu verringern. Frauen sollten aufgrund ihrer hohen Übergewichtsraten im Zentrum dieser Kampagnen stehen. Darüber hinaus sollte ihre Position als Entscheidungsträger wegen ihrer wichtigen Rolle für die bessere Verteilung von Ressourcen innerhalb des Haushaltes weiter gestärkt werden.

Partnerschaften zwischen dem öffentlichen und dem privaten Sektor können wichtig sein, wenn Maßnahmen in der Nahrungsmittelindustrie zur Verminderung des Konsums von Zucker, Fetten und Salz in Betracht gezogen werden. Außerdem ist die Verbesserung des Gesundheitssystems wichtig, damit der Gesundheitszustand besser überwacht werden kann und auch versteckte Mangelernährung besser diagnostiziert werden kann, die die Ungleichheit auf Haushaltsebene verstärkt. 


\section{ACKNOWLEDGEMENTS}

Several people accompanied and supported me during the work on my dissertation. First and foremost, I am thankful to Professor Dr. Matin Qaim to giving me the opportunity to conduct research at his chair and in this field. Further, I am grateful to Dr. Holger Seebens who first assisted in supervising me at the chair. I thank also Professor Stephan Klasen, PhD for being my second supervisor and Junior-Professor Dr. Meike Wollni to be the third member of my examination committee. Moreover, I thank all people at the chair that always helped me out in all relevant questions and spent lots of time with me. Special thanks in this regard go to Christin, Christoph, Sarah, Summer, Shahzad and Lisa.

I am very thankful to all my very good friends from Göttingen that had their everyday life with me. Thank you: Malte, Matthias, Nora, Martin, Alexandra, Friederike and Iris. Special thanks go to my best friends that always pushed me, supported me and helped me out, thank you Elke, Inga and Maya. I thank also my family (my sister Stefanie, my mother and my father) and my family from home: Meike, Anna, Anita, Sandra, Millena, Michaela, Frauke and Sarah. You all always supported me, followed every (career-) step in my life and I always found patient listeners in you for any problem. Finally, I thank Timo for being there for me and planning his life with me. 


\section{TABLE OF CONTENTS}

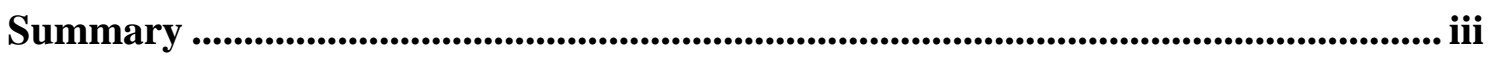

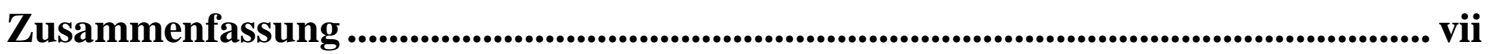

Acknowledgements .................................................................................................................. xii

Table of contents................................................................................................................. xiii

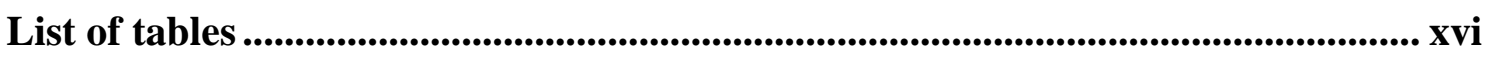

List of figures ......................................................................................................................... xvii

Abbreviations ............................................................................................................................... Xviii

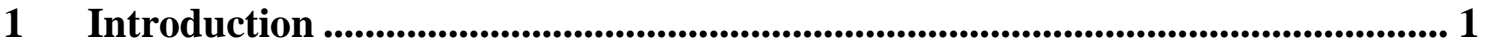

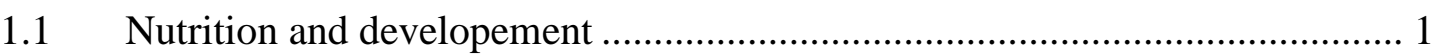

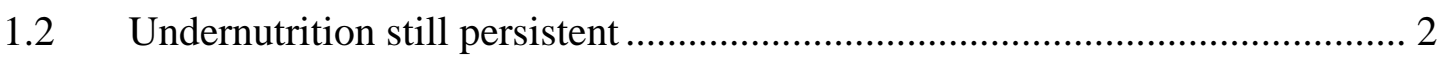

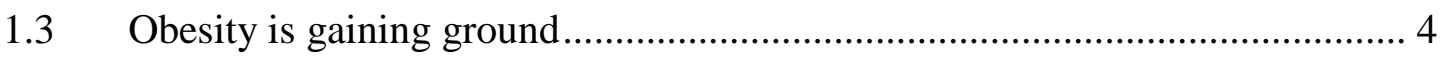

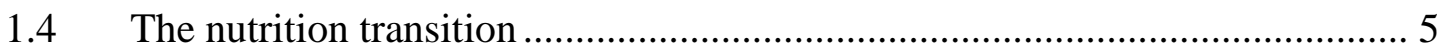

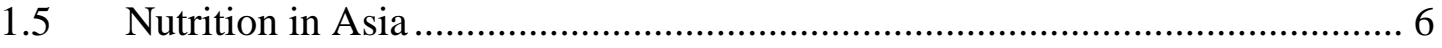

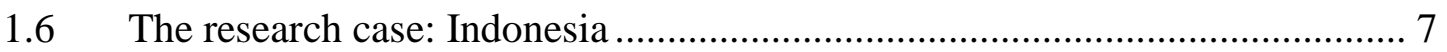

$1.7 \quad$ Problem statement and research objectives ............................................ 9

2 Obesity trends and determinants in Indonesia ......................................... 11

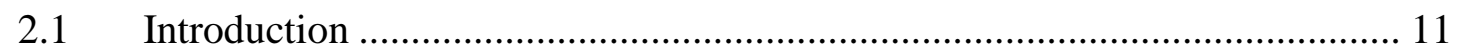

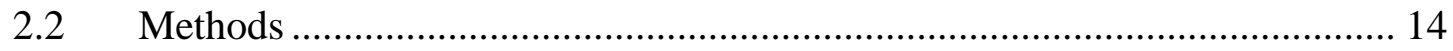

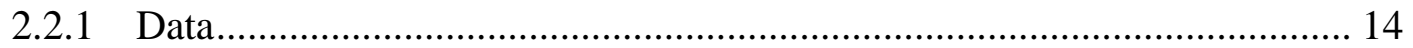

2.2.2 Statistical approach of data analysis ................................................. 15

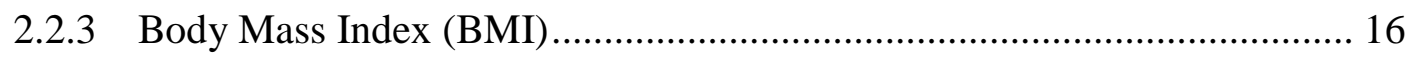




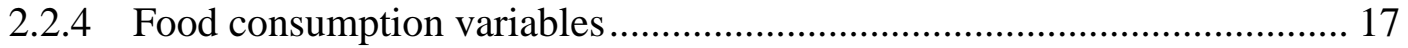

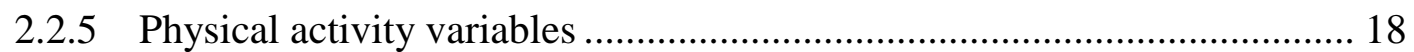

2.2.6 Other socioeconomic variables............................................................. 19

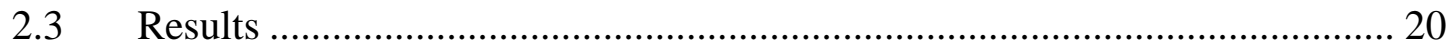

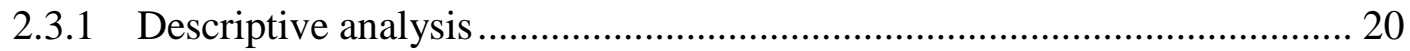

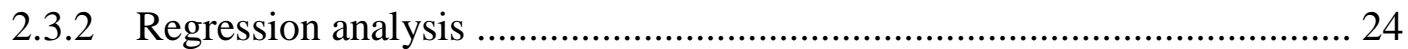

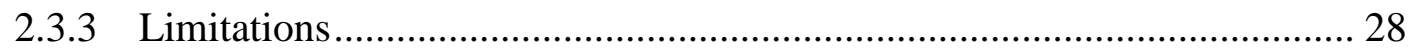

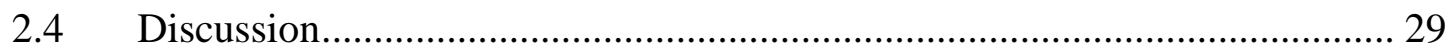

3 Dual burden households and nutritional inequality in Indonesia.................... 32

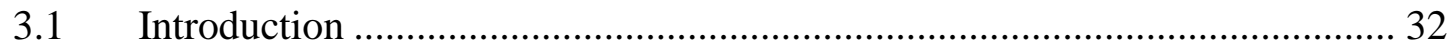

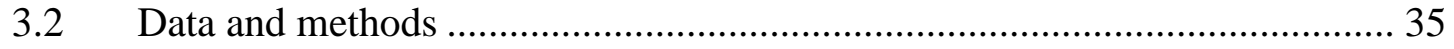

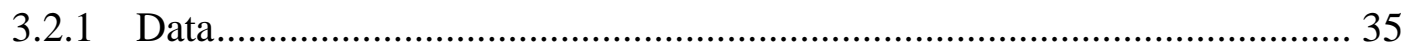

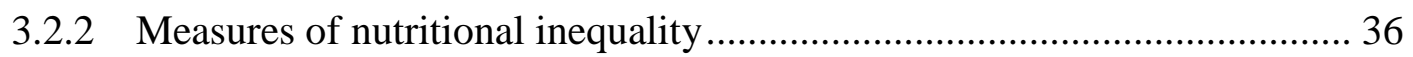

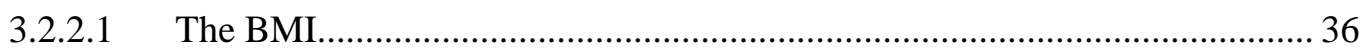

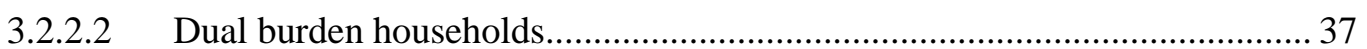

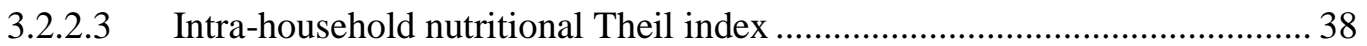

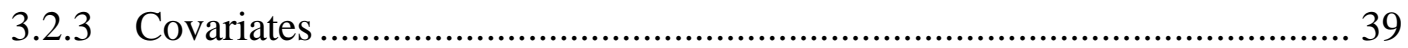

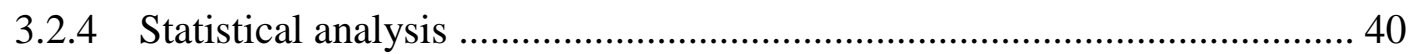

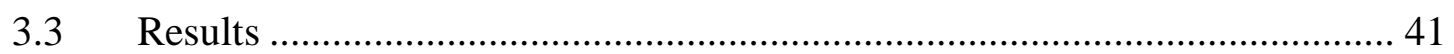

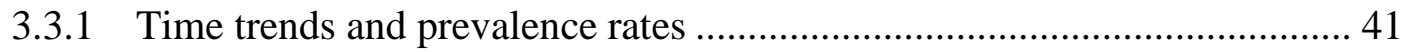

3.3.2 Descriptive analysis of socioeconomic factors .................................... 45

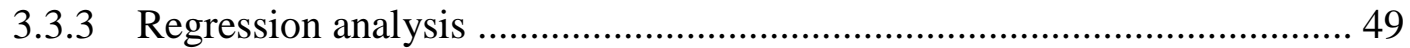

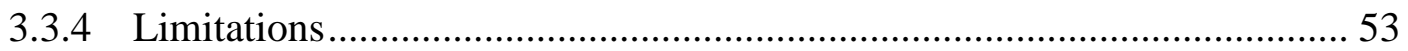

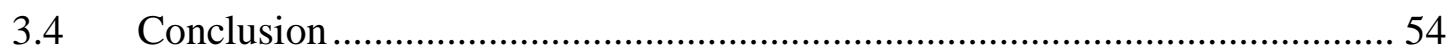

4 Conclusion ....................................................................................................................... 57 


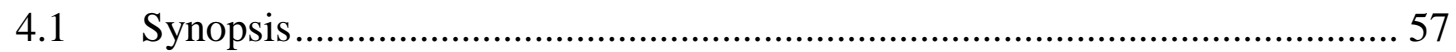

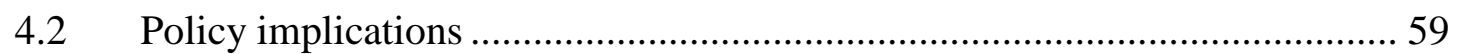

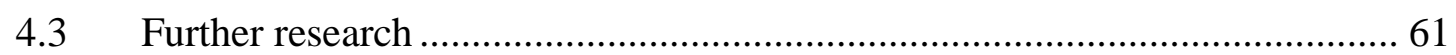

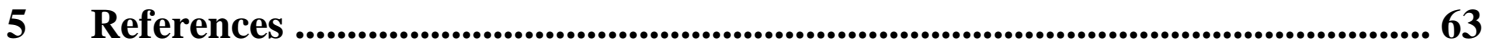

$6 \quad$ Appendix .................................................................................................................. 73 


\section{LIST OF TABLES}

Table 1: Sample size for adult individuals and percentages by gender and location (20 to

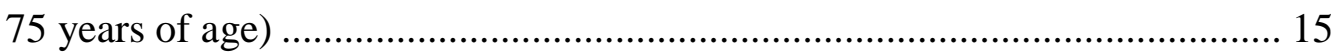

Table 2: BMI and change in BMI by gender and location ....................................... 20

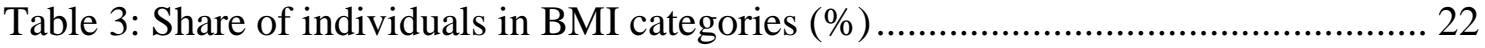

Table 4: Food expenditures, household appliances, and television ownership by nutritional status $(1993,2000$, and 2007) 23

Table 5: Panel regressions explaining BMI (2000 and 2007) ......................................... 26

Table 6: Household categories of nutritional outcome................................................. 42

Table 7: Nutritional Theil index at household level over time and rural/urban location 42

Table 8: Transition matrix: Transition over time between the BMI household categories

Table 9: Mean number of underweight and overweight household members by age group and BMI household category

Table 10: Theil index and nutrition transition characteristics ................................... 47

Table 11: Intra-household nutritional inequality and gender of household head 48

Table 12: Panel random effects probit estimation for household categories (marginal effects) 50

Table 13: Panel regressions with Theil index. 51 


\section{LIST OF FIGURES}

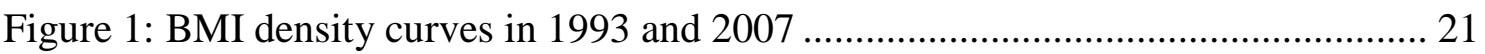

Figure 2: Share of population in BMI categories over time (in \%) ............................... 22

Figure 3: Work-related physical activity and BMI category (1993, 2000, and 2007) ... 24

Figure 4: Intra-household nutritional Theil index over time and household BMI category

Figure 5: Household BMI categories by expenditure quintile 46 


\section{ABBREVIATIONS}

$\begin{array}{ll}\text { BAPPENAS } & \text { Indonesian National Development Planning Agency (Badan } \\ \text { BMI } & \text { Perencanaan dan Pembangunan Nasional) } \\ \text { BPS } & \text { Body Mass Index } \\ \text { FAO } & \text { Indonesian Bureau of Statistics (Badan Pusat Statistik) } \\ \text { HDI } & \text { Food and Agriculture Organization } \\ \text { IFLS } & \text { Human Development Index } \\ \text { IFPRI } & \text { Indonesian Family and Life Survey } \\ \text { MDG } & \text { International Food Policy Research Institute } \\ \text { SUSENAS } & \text { Millennium Development Goals } \\ & \text { Endonesian National Socioeconomic Survey (Survei Sosial } \\ \text { UNDP } & \text { United Nations Development Programme } \\ \text { UNICEF } & \text { Wnited Nations Children's Fund } \\ \text { WHO } & \text { World Health Organization }\end{array}$




\section{INTRODUCTION}

The world is facing the challenge of providing decent living conditions for the population in all countries. In particular, the developing world is still struggling with many problems in terms of health, education and earning opportunities of their populations. More than 22 percent of the global population lives on less than $\$ 1.25$, the poverty line for extreme poverty (World Bank, 2012). While progress has been made in recent years, many challenges remain. Overweight and obesity are new concerns of developing countries leading to changing disease burdens and new policy challenges. Because undernutrition is still a concern, countries are faced by a dual burden of nutrition, sometimes even at household level. This study conducts a detailed country study to gain new insights about the nature of the problem. Trends and determinants are carefully investigated to derive possible policy strategies to cushion negative consequences.

\subsection{NUTRITION AND DEVELOPEMENT}

Good nutrition, is one cornerstone determining health but it also influences education and earning opportunities (Glewwe and Miguel, 2007). Malnutrition creates losses in cognitive ability, schooling outcomes, and work productivity, in addition to 
causing significant health costs (World Bank, 2006). This can lead to a vicious cycle where high health costs and diminished productivity trap individuals in poverty.

Nutrition is crucial since malnutrition is assumed to be responsible for 60 percent of deaths and 47 percent of diseases all over the world (World Bank, 2006). Malnutrition can exist in the form of underweight, overweight and hidden hunger (lack in micronutrients). In total about two billion people are affected by either underweight or overweight (FAO, 2012; Kelly et al., 2008). Micronutrient deficiencies are often undetected and can only hardly be estimated. Black et al. (2008) calculate one million deaths among children under five only from vitamin A and zinc deficiency in 2004. While micronutrient deficiencies and underweight are associated with growth retardation and higher vulnerability to communicable diseases, overweight is often connected with non-communicable diseases like cardio-vascular diseases or diabetes.

Many global institutions like World Bank, World Health Organization (WHO), Food and Agriculture Organization (FAO), International Food Policy Research Institute (IFPRI) and mandates such as the Millennium Development Goals emphasize the importance of nutrition (e.g., FAO, 2012; UN, 2006; WHO, 2000; World Bank, 2006). The focus on nutrition is also interesting since returns to investment in nutrition improvement are high in comparison with other policy actions (CCC, 2004).

\subsection{UNDERNUTRITION STILL PERSISTENT}

Undernutrition has long been one main topic in development strategies. It is the most visible sign for development deficits. Underweight has been a problem in all developing countries for a long time. More than 1 billion people suffered from hunger or undernourishment in 2009 (FAO, 2011). Still, undernourishment has been reduced gradually since the 1960s and only in recent decades have we seen a slow increase in total numbers (but less so in relative numbers). The most recent figure of 2010 shows again a 
reduction since 2009 and states that 16 percent in developing countries are undernourished (FAO, 2011). In the developed world the underweight rate is under 2 percent (de Onis et al., 2004).

Asia and Africa are the continents with highest undernutrition rates in children. The most recent rates show Southeast and South Central Asia at about 28 percent and 18 percent, respectively (de Onis et al., 2004). In Africa, the prevalence rates among children have been twice as high. There, progress is not so dynamic; the prevalence rates even increased from 1980 to 2005, mainly because of rising rates in East Africa (de Onis et al., 2004; World Bank, 2006).

Increasing incomes can help to lower malnutrition especially in adults but children often remain underweight or stunted even if the household is food secure (World Bank, 2006). Lacking knowledge about proper infant feeding and care as well as poor healthcare and sanitation are main factors (World Bank, 2006). While in the past, the main focus was on protein and energy deficiencies, over time it has become obvious that micronutrient deficiency is a major factor crucial for development and productivity (Allen, 2003). Even mild micronutrient deficiencies in underweight and also in overweight individuals can be harmful (Asfaw, 2007b). In addition, higher obesity rates can be connected with higher levels of micronutrient deficiencies (García et al., 2009).

Vitamin A, iodine and iron deficiency are the nutrient deficiencies that are most widely spread and with severe consequences (Allen, 2003). Weakened immune systems, blindness, children's or mothers' death during pregnancy and mental impairments are connected with these deficiencies. This damage often occurs in pregnancy or in the first years of life and is irreversible. Direct losses are seen in productivity from poor physical status and additional health care costs; indirect losses result from cognitive and schooling problems (World Bank, 2006). Malnutrition helps promote the spread of diseases since the 
body cannot fight infections such as HIV/AIDS, malaria, tuberculosis, among others (World Bank, 2006). This leads to lower productivity and makes poverty more persistent.

To further fight this problem, it is not only important to supply enough food in the country but also to support the entitlement of individuals and households. Individuals need to earn enough income to buy adequate food or have enough resources to produce their food. This is also one main point raised and developed by nobel laureate Amartya Sen. His concept of entitlements highlights the importance of not only availability of food but also accessibility (Sen, 1981). Together with Jean Drèze, he elaborates that hunger is not the lack of affluence in countries but rather the unequal distribution of income (Drèze and Sen, 1989). This is where development strategies have to adapt so that supply is ensured and individuals can earn enough income to afford the food needed. However, the newly emerging problem of obesity in developing countries (even in the lower income strata) challenges the sufficiency of this approach alone.

\subsection{OBESITY IS GAINING GROUND}

There is an increase in overweight and obesity all over the developing world. As with many transitions seen in development, Latin America is the continent where the shift to overweight has first been found and still exists side by side with undernourished children and stunted children (Rivera et al., 2004; Uauy et al., 2001). Also North African countries and the Middle-East region show highest obesity rates at levels comparable with Europe or the United States (Galal, 2003; Mokhtar et al., 2001). Now overweight is higher than underweight in many developing countries especially with respect to women (Mendez et al., 2005; WHO, 2000). Even in many African countries overweight exceeds underweight especially in urban areas (Mendez et al., 2005). In African children one can see a dramatic increase over the years especially connecting maternal overweight to child 
overweight (de Onis et al., 2010). It has become clear that obesity is not only limited to developed countries (James et al., 2001; Popkin and Doak, 1998; Prentice, 2006).

This new problem of obesity, at a time when underweight has not yet been eradicated, creates a new challenge for policymakers in developing countries. They have a dual burden at the country level and strategies may act counter-effective when only considering one of these problems. For example we see in Northern Africa and Central America equally high overweight and wasting (weight-for-height) rates among children but also in other countries both problems exist even though to a lesser extent (de Onis et al., 2010). Also for the adult population similar outcomes can be found. For example in countries like Ghana, Kenya or Ivory Coast the prevalence rates of overweight and underweight for women are both about 10 percent in rural areas (Mendez et al., 2005). This makes policy strategies extremely difficult.

Another problem is that this dual burden is not only found at the country level but also at the household level (Doak et al., 2005; Doak et al., 2000). That is, some households have members who are overweight, while other members are underweight. This underlines that there is substantial intra-household nutritional inequality, the determinants of which are not yet fully understood. Intra-household inequality certainly also complicates targeting of policies and interventions. Better understanding the trends and determinants is important from research and policy perspectives.

\subsection{THE NUTRITION TRANSITION}

These newly emerging problems seem to be associated with changes in consumption and physical activity that are often referred to as the 'nutrition transition' (Popkin et al., 2012). Rising incomes, urbanization and globalization lead to a change in lifestyle. While food availability is improving and diets get more diverse, the content of fat and sugar is increasing in food consumption. Meat and dairy products as well as processed 
foods are becoming part of the daily diet (Delgado, 2003). To some extent, these developments may be driven by the spread of supermarkets, although the evidence is not yet conclusive. Supermarkets are playing a more important role in developing countries, changing the availability and price structure of food (Reardon et al., 2003). It is also becoming more common to eat away from home in canteens, restaurants, and fast-food outlets, which often serve calorie-dense but otherwise less nutritious foods.

Physical activity also changes dramatically in several regards. On the one hand, occupations are less strenuous given that many are employed in the service sector in sedentary jobs. Additionally, leisure time activities change. Internet, video games and television are gaining popularity and are becoming more affordable for large parts of the populations, including poorer income segments. Moreover, physical activity associated with household chores and transport is getting more and more comfortable. Appliances like washing machines, vacuum cleaners and mixers are helping in the household. Improvements of transport systems and ownership of motorbike and cars are easing transport to work or school. This is especially supported by migration into urban areas and urbanization of former rural areas.

\subsection{NUTRITION IN ASIA}

Many Asian countries show extraordinary economic development, which goes side by side with reduction in poverty rates and increases in living standards as well as signs of nutrition transition. Economic development helps to improve nutrition in these areas with high levels of underweight. This is found in several studies (Dearth-Wesley et al., 2008; Kosulwat, 2002; Lee et al., 2007; Popkin et al., 2001).

The number of underweight children is decreasing in Asia and is estimated to keep falling (de Onis et al., 2004). However, within Asia there are large differences in nutrition levels. In South Asia (India, Bangladesh, Nepal and Pakistan), the rates of undernutrition 
are even higher than in Africa. In contrast, in East Asia, especially China, prevalence rates are much lower and consistently declining. This is also true in Cambodia, Indonesia, Lao DRP, the Philippines and Vietnam (de Onis et al., 2010). Malaysia and Thailand are very advanced for the region in terms of nutrition. Still, most of the improvements in global undernutrition rates are driven by China's extreme reduction. In addition, even though countries like India, Bangladesh and Nepal are characterized by underweight in general, overweight and obesity are increasing (Balarajan and Villamor, 2009).

\subsection{THE RESEARCH CASE: INDONESIA}

Indonesia is one of the most populous countries in the world and the third populous developing country following India and China (World Bank, 2010). The development of Indonesia in recent decades has been characterized by the beginning of a democratic society and by a financial crisis in 1997, which greatly impacted the country. The process of the country into democracy is still ongoing. While elections have been held, political corruption is still a big problem. Further, Indonesia shows increasing incomes and poverty reduced to 13 percent in 2010 (World Bank, 2012). The general trend is a decrease in poverty, even though after the crisis and after 2005, because of soaring prices, poverty increased for a short time (BPS et al., 2004; World Bank, 2012).

A broader analysis of poverty using the Human Development Index (HDI), which also includes education and health indicators, shows significant improvements. From the 1970s to 2000, the HDI rose steadily from about 0.5 to just below 0.7 (BPS et al., 2004). Of course, improvements are not as large as seen with income, since indicators are not as volatile in the short-term. Although differences between provinces exist, there are more significant differences between major cities and rural areas. In general, child underweight measurements and mortality have decreased, life expectancy rose, literacy rates rose to about 99 percent and education levels increased (BPS et al., 2004). 
However, underweight and stunting rates are high, maternal mortality is high and public healthcare quality is poor (BPS et al., 2004). One cause could be that public expenditures for health and education are much lower than in other developing countries (World Bank, 2010). The World Health Report 2011 notes that Indonesia is situated between China and India for most health indicators and has a higher share of the population that die from non-communicable diseases than India (WHO, 2011). China has seen extreme progress concerning malnutrition, while India has still extremely high undernutrition and stunting rates (UNICEF, 2012a, 2012b, 2012c). With regard to the newer nutrition issues, Indonesia is seeing increasing overweight and obesity rates (Collins et al., 2008; Usfar et al., 2010) as well as further changes in food consumption and dual burden households (Doak et al., 2005; Lipoeto et al., 2004).

As the role of women can play important roles for family nutritional outcomes, it is important to note that the role of women in Indonesia is relatively equal to that of men and equal by law. Education levels are about equal. For women, life expectancy is higher and labor market participation was at 38 percent in 2002 (BPS et al., 2004). However, maternal mortality is very high due to the problems in the healthcare system mentioned before.

The Indonesian government has implemented many policies to reduce nutritional and health problems leading to child and maternal mortality. For example, the government agreed to provide minimum healthcare to children and women. A nutrition intervention program was launched to decrease the four major nutrients that contribute to nutritional deficiency in Indonesia: protein, iron, vitamin A and iodine (Kurniawan, 2002). Even though progress has been made, Indonesia is spending less on these problems than other similar countries and the policies are not implemented very efficiently (OECD, 2010). 


\subsection{PROBLEM STATEMENT AND RESEARCH OBJECTIVES}

Incomes are increasing in developing countries and urbanization continues, while globalization spreads the availability of different types of food. At the same time, lifestyles are changing and overnutrition is becoming a serious issue in developing countries, with more and more countries seeing increasing rates. Policies in all countries mostly focus on undernutrition. Even though hunger is clearly a problem that needs to be cared for cautiously, nutrition education should accompany measures to increase calorie input. Policy strategies need to adapt to recent increases in overweight that also represents malnutrition.

Indonesia has not been much in the focus of research with respect to nutrition transition or obesity although it is one of the most populous developing countries. However, quite a bit of research has been conducted on China and India, the biggest and fastest growing countries in the region.

The first part of this study focuses on the development of nutrition in Indonesia over time. First, the following two research questions are analyzed:

(1) Is overweight and obesity a problem in Indonesia?

(2) What are the time trends and determinants of nutritional status?

While Indonesia has long been known for high undernutrition, stunting and poverty rates, a dual burden at the country level is evident and most probably also exists at the household level. Therefore, the second part of this research focuses on the overweight and underweight problem combined. The second set of questions is thus: 
(3) What is a good measure for intra-household nutritional inequality?

(4) What are the trends and determinants of intra-household nutritional inequality in Indonesia?

We use panel data from the Indonesian Family and Life Survey (IFLS) for elaborating these questions. The survey from the Rand institute has been conducted in 1993, 1997, 2000 and 2007. The data offers information on health, anthropometric measurements of adults and children, and detailed information on various socioeconomic characteristics, including household level assets and expenditures, and individual level employment. The combination of panel data and the rich information makes it very useful in our context. Especially for developing countries such rich datasets with panel structure do not often exist. For further information on the data see subchapters 2.3.1 and 3.2.1.

Our study is structured as follows: Chapter 2 analyzes the occurrence of overweight and obesity in Indonesia and sheds light on its determinants, looking at time trends and the relationship with expenditures. Several other socioeconomic variables are also included and tested in panel regressions for the association with the Body Mass Index (BMI).

Chapter 3 focuses on our second set of research questions, calculating and developing measures for intra-household nutritional inequality. We analyze in depth the occurrence of dual burden households and intra-household nutritional inequality with the Theil index. Furthermore, we focus on the determinants of inequality, especially expenditures and the gender of the household head. Panel regressions are also conducted to control for several covariates.

The last chapter draws conclusions from our research. 


\section{OBESITY TRENDS AND DETERMINANTS IN INDONESIA ${ }^{1}$}

\subsection{INTRODUCTION}

For quite some time, overweight and obesity were considered primarily problems of developed countries. However, with increasing incomes, urbanization, and changing lifestyles, it is obvious that developing countries are facing the same issues (e.g., GerbensLeenes et al., 2010; Jones-Smith et al., 2011b; Popkin, 2010). A major difference is that in developing countries relatively little attention is paid by policymakers to the problem of excessive weight gain; it is often still perceived rather positively and associated with higher social status. Given that obesity contributes to a variety of serious chronic diseases and thus to a large health burden (e.g., WHO, 2000), its spread hampers human welfare and economic development (Pinstrup-Andersen, 2007). Developing countries that already have high obesity prevalence rates are mainly found in Latin America (Lobato et al., 2009; Rivera et al., 2004; Vio et al., 2008), the Middle East, and North Africa (Mehio Sibai et al., 2010). But also in Asia and Sub-Saharan Africa, where undernutrition is still more prevalent, obesity is rising, causing a double burden of malnutrition. The emergence of this

1 This chapter is published as a journal article in "Appetite" (2012), http://dx.doi.org/10.1016/j.appet.2012.02.053. The co-author of the article is Matin Qaim, Prof. of the Department of Agricultural Economics and Rural Development, Georg-August-University of Göttingen, 37037 Göttingen, Germany. 
paradox is reinforced by the so-called nutrition transition. This term comprises food consumption and physical activity changes that are associated with lifestyle transformations in modernizing societies (Popkin, 2003). Whereas in developed countries this process occurred gradually, in many developing countries it proceeds at a much faster rate. Further, childhood stunting was found to be positively associated with adult obesity (e.g., Hoffman et al., 2000; Olson et al., 2007), making developing countries especially vulnerable. Containing the obesity pandemic through appropriate policies requires a better understanding of the trends and their underlying determinants in particular settings.

The literature on socioeconomic aspects of obesity is growing, but many of the studies focus on developed countries (Chan and Sobal, 2011; Lakdawalla and Philipson, 2009; Offer et al., 2010; Penman and Johnson, 2006; Williams et al., 2011). These findings are also interesting for developing countries, but they cannot be extrapolated directly, because of very different framework conditions. Several recent studies have also focused on developing countries. Jones-Smith et al. (2011b) and Subramanian, Perkins, Oezaltin, \& Davey-Smith (2011) have used Demographic and Health Surveys of various low and middle income countries to analyze the relationship between socioeconomic status and weight change. While obesity prevalence rates increase with wealth and education in low income countries, poorer and less educated people are also increasingly affected. Another study by Case and Menendez (2009) examined the importance of gender aspects for obesity prevalence rates in South Africa. Asfaw (2007a) and Asfaw (2008) looked at the role of food prices and location of food purchases for obesity and dietary practices in Egypt and Guatemala, respectively.

One problem with existing obesity research in developing countries is that most studies build on cross-section data, such that trends and nutritional shifts over time have rarely been analyzed. A second problem is the main focus on wealth and education, especially in those studies that build on large and representative data sets. While wealth 
and education are certainly important, there may be additional determinants, such as food consumption choices, physical activity, or related behavioral variables. When such additional determinants are correlated with wealth or education, omitting them in regression models may lead to biased results and conclusions. Unfortunately, representative surveys that contain anthropometric data needed for obesity analysis do usually not provide sufficient details on food consumption, physical activity levels, and other socioeconomic factors (de Haen et al., 2011). Notable exceptions for both problems include several studies for China, where the China Health and Nutrition Surveys provide a useful data base for analyzing obesity dynamics and behavioral determinants (Jones-Smith et al., 2011a; $\mathrm{Ng}$ et al., 2010; $\mathrm{Ng}$ et al., 2009).

We contribute to the literature by analyzing obesity trends and determinants in Indonesia, where suitable panel data are available. Indonesia is an interesting case to study also for several other reasons. First, Indonesia is a large and populous country and one of the economically fast growing nations of Asia, so that significant nutritional dynamics can be expected. Recent research suggests that obesity rates are increasing in the country (Usfar et al., 2010). Lipoeto (2004) revealed a notable shift in causes of death from infections to cardiovascular diseases. Second, rapid urbanization and a transformation of traditional food systems towards modern supply chains can be observed in Indonesia (World Bank, 2007). Third, unlike China and a few other countries, for which more research is already available, Indonesia is a country with a high share of Muslim population. This may play a role for the direction of lifestyle changes, especially when considering gender differences. Thus, Indonesia may offer interesting insights into developments that are likely to occur also in several other Muslim-dominated Asian countries that are still at earlier stages of economic development.

The rest of this article is structured as follows. The next section discusses the data from Indonesia and the analytical approach. Then, we present descriptive results, focusing 
on obesity trends in male and female adults. Subsequently, we estimate panel regression models to analyze obesity determinants. The last section concludes.

\subsection{METHODS}

\subsubsection{DATA}

Our analysis builds on data from the Indonesian Family and Life Survey (IFLS) of the RAND Corporation, an international public policy research institute headquartered in the USA. IFLS survey waves were conducted in 1993, 1997, 2000, and 2007, offering a panel structure. While in the sampling framework a few remote areas were not included, the data are representative for $83 \%$ of the Indonesian population. Out of a total of 27 provinces then, 13 were selected for the IFLS, including four provinces in Sumatra (North Sumatra, West Sumatra, South Sumatra, and Lampung), all five provinces in Java (DKI Jakarta, West Java, Central Java, DI Yogyakarta, and East Java) and the following four provinces: Bali, West Nusa Tenggara, South Kalimantan, and South Sulawesi. The choice of provinces was influenced by cost considerations for implementing the surveys, yet without compromising coverage of socioeconomic and ethnic diversity (Strauss et al., 2009). Within the selected provinces, villages and households were sampled building on the National Socioeconomic Survey (SUSENAS) sampling frame of the Indonesian Bureau of Statistics (BPS). The data are representative at province level. For more detailed information on the sampling frame, see Frankenberg and Karoly (1995), Strauss et al. (2004), and Strauss, Witoelar, Sikoki, \& Wattie (2009). The survey includes data on health, anthropometric measurements of adults and children, and detailed information on various socioeconomic characteristics, including household level assets and expenditures, and individual level employment. 
Table 1: Sample size for adult individuals and percentages by gender and location (20 to 75 years of age)

\begin{tabular}{cccccc}
\hline Year & Total & Male & Female & Rural & \multicolumn{2}{c}{ Urban } \\
& & $\boldsymbol{\%}$ & $\boldsymbol{\%}$ & $\boldsymbol{\%}$ & $\%$ \\
\hline $\mathbf{1 9 9 3}$ & 10,227 & 0.46 & 0.54 & 0.55 & 0.45 \\
$\mathbf{2 0 0 0}$ & 17,041 & 0.49 & 0.51 & 0.52 & 0.48 \\
$\mathbf{2 0 0 7}$ & 20,475 & 0.48 & 0.52 & 0.48 & 0.52 \\
\hline
\end{tabular}

Source: IFLS1, IFLS3, IFLS4

The analysis here concentrates on male and female adults aged 20 to 75 . We do not include children and adolescents, because nutritional determinants can be quite different for these age groups. For example, we look at work-related physical activity, which is not relevant for most children. Moreover, the body mass index (BMI), which is the most widely used indicator of nutritional status among adults, is less appropriate for children (WHO, 1995). We use data from three of the four IFLS waves, namely 1993 (IFLS1), 2000 (IFLS3), and 2007 (IFLS4). We decided not to use the 1997 (IFLS2) data for two reasons. First, in 1997 Indonesia was undergoing a severe economic and financial crisis. This affected household living standards harshly (e.g., Suryahadi et al., 2003; Thomas and Frankenberg, 2007) and could thus lead to ambiguous results in the trend analysis. Second, focusing on 1993, 2000, and 2007 means having equal time intervals between the survey waves, which is advantageous when analyzing and interpreting nutritional dynamics.

The sample size has grown over time, because additional household members were born or interviewed, and split-off households were tracked in the survey (Table 1). The sample used for our analysis includes only individuals for whom complete data on all variables of interest are available.

\subsubsection{STATISTICAL APPROACH OF DATA ANALYSIS}

This study investigates nutritional status of Indonesian working age adults as well as trends and determinants with descriptive analysis and panel regression models. We 
consider food consumption, physical activity, and other socioeconomic variables to be the main influencing factors of nutritional outcome, measured in terms of the body mass index (BMI). Regression analysis may suffer from endogeneity bias, as nutritional outcomes and socioeconomic determinants might be jointly influenced by unobserved factors ( $\mathrm{Ng}$ et al., 2010). Fixed effects models can control for unobserved heterogeneity, thus controlling for one possible cause of endogeneity (Baltagi, 2005). However, with fixed effects models one cannot efficiently estimate the influence of socioeconomic variables for which no or only very little variation is observed over time for individuals. Examples in our context include education, occupational characteristics, or household location. Hence we estimate both fixed and random effects models.

The variables employed in the analysis are explained below. For the regressions, we only use 2000 and 2007 data, because some explanatory variables of interest were not included in the 1993 survey. Sample mean values are shown in Appendix 1. We estimate separate models for male and female adults, as the descriptive analysis suggests that gender differences in the estimation coefficients may be expected. Robust and cluster corrected standard errors at individual level are used to correct for possible heteroskedasticity and error correlation.

\subsubsection{BODY MASS INDEX (BMI)}

The BMI - defined as the body weight in kilograms divided by the squared body height in meters - is used here as the indicator of adult nutritional status. It should be mentioned that the BMI has some drawbacks in identifying body fat and obesity for people of certain stature; yet it is the most widely used indicator of adult nutritional status and the only one for which comparable data are usually available (WHO, 2000).

Part of the descriptive analysis requires classification of individuals by BMI categories. BMI categories and cut-off levels for undernourished, normal, and overweight 
individuals have been set internationally based on a Caucasian reference population. However, this Caucasian reference population may not properly reflect the situation for other ethnic groups. Research suggests that increased risk of chronic diseases and overweight-related mortality are associated with lower BMI levels in Asians than in other populations (WHO, 2004). Gurrici, Hartriyanti, Hautvast, \& Deurenberg (1998) calculated the cut-off value for obesity in Indonesian adult populations at 27 (instead of 30). Using this in combination with data from WHO (2004), we categorize a BMI of higher than 27 as obese, and between 23 and 27 as preobese. These two categories together - i.e., the population with a BMI over 23 - are also referred to as overweight. Accordingly, a BMI between 18.5 and 23 is categorized as normal weight, whereas less than 18.5 is considered underweight. For comparison, we additionally use the international BMI cut-off values of 25 for overweight and 30 for obesity.

\subsubsection{FOOD CONSUMPTION VARIABLES}

Food consumption patterns influence nutritional outcomes, but they are often not included in obesity research building on secondary surveys due to data constraints. Aspects of both food quantity and diet composition are expected to play a role. For instance, the more fat and sugar the diet contains, the higher is the risk of gaining excess weight. This is often associated with highly processed foods and beverages. With rising incomes, urbanization, global advertising, and the spread of supermarkets and fast-food outlets, an increasing number of households consumes meat, dairy products, and highly processed convenience and junk foods, replacing traditional foods with higher fiber contents (Hawkes, 2008; Popkin, 2003).

We proxy individual level food consumption with household per capita food expenditures. Unfortunately, physical quantities of food consumed are not available in IFLS. The surveys capture food expenditures in terms of the value of consumption during 
one month measured in Indonesian rupiah. In addition to market purchases, the value of home-produced foods and food transfers is considered. To account for dietary composition, we also include the food expenditure share spent on meat and dairy products, expecting that a higher share is associated with higher BMI. Furthermore, we include the food expenditure share spent on traditional staple foods, such as rice, corn, flour, and root and tuber crops, but not further processed foods such as noodles and bread. Unprocessed staples play a bigger role in traditional diets and are expected to lose in relative importance during the nutrition transition. Information about the sugar, fat, and salt content of foods and diets, which is expected to increase in the course of the nutrition transition, is not available in the dataset. Because Indonesia is characterized by a high share of Muslim population, alcohol consumption is very low and not considered in this analysis.

\subsubsection{PHYSICAL ACTIVITY VARIABLES}

In addition to food consumption, physical activity during work and leisure time is expected to influence BMI. Decreasing employment in agriculture, urbanization, and a general trend towards a service sector economy imply lower physical occupational activity, a process that occurs at high speed in many developing countries (Monda et al., 2007; $\mathrm{Ng}$ et al., 2009). To proxy work-related activity, we use information about the occupation of individuals included in IFLS. The data contain 100 different occupation codes, which we categorize into four physical activity groups, building on a classification system used previously (Lu and Goldman, 2010; Norman et al., 2002). These four groups are sedentary jobs, and jobs with light, medium, and heavy physical activity. As not all individuals are working, two additional categories for housekeeping and unemployed are used (Appendix $1)$.

Leisure-related physical activity includes household work and free time that can be used for hobbies and pleasure. Household work becomes easier in the process of economic 
development, due to wider availability of electricity, piped water, private means of transportation, and household appliances, such as washing machines, fridges, and vacuum cleaners. The value of such household appliances was captured in the survey and is used here as a proxy. Free time is sometimes used for sports and other physical exercise. However, this is not yet very widespread in Indonesia, which is partly due to climatic and cultural factors. Instead, the popularity of watching television, playing videogames, and using the internet is increasing. Unfortunately, pleasure activities are not properly captured in the IFLS. We use a dummy that measures whether or not a household possesses a television as a proxy for free time activities. While this is an imperfect measure, ownership of a television increases the tendency towards more sedentary lifestyles and may reduce the time spent on more active hobbies (Du et al., 2002). The variable is not used as a measure for household wealth or living standard, as nowadays television ownership is relatively widespread in Indonesia, and the correlation with income is relatively weak. Variables that capture living standard are described in the following.

\subsubsection{OTHER SOCIOECONOMIC VARIABLES}

Income and socioeconomic status contribute to higher BMI in developing countries (Fernald, 2007; Jones-Smith et al., 2011b; Ma, 2010). This relationship may be multifaceted. Especially in countries with widespread undernutrition, higher incomes and better education are expected to contribute to more food consumption and higher dietary diversity. Furthermore, household living standard often influences physical activity levels. There may also be effects related to more frequent media use and other related factors. We use total expenditure levels per capita (for consumption of all food and non-food goods and services) as the main indicator of living standard. In addition, educational levels are measured in terms of four categories, from zero indicating no education, to 3 indicating completed university education. We also include a dummy for rural location. In spite of 
ongoing urbanization processes in Indonesia, about half of the population still lives in rural areas. Finally, dummies for marital status and smoking are considered in the regression analysis. Smoking increases body metabolism and reduces appetite (Chiolero et al., 2008). Summary statistics of all variables described are shown in Appendix 1.

\subsection{RESULTS}

\subsubsection{DESCRIPTIVE ANALYSIS}

Mean BMI in Indonesian adults has increased notably since 1993 (Table 2). Women in Indonesia have a higher mean BMI than men, with the difference growing over time. This gender difference is more pronounced than in China. While rural men and women have a lower mean BMI, the increase over time is stronger than among the urban population. An increase in BMI may indicate either an improvement or a deterioration of nutrition status, depending on the starting point.

Table 2: BMI and change in BMI by gender and location

\begin{tabular}{|c|c|c|c|c|c|c|c|c|}
\hline \multirow[b]{3}{*}{ Year } & \multicolumn{4}{|c|}{ Male } & \multicolumn{4}{|c|}{ Female } \\
\hline & \multicolumn{2}{|c|}{ Urban } & \multicolumn{2}{|c|}{ Rural } & \multicolumn{2}{|c|}{ Urban } & \multicolumn{2}{|c|}{ Rural } \\
\hline & Mean & SD & Mean & SD & Mean & SD & Mean & SD \\
\hline 1993 & 21.80 & 3.21 & 20.48 & 2.48 & 22.77 & 3.92 & 21.05 & 3.21 \\
\hline 2000 & 21.84 & 3.47 & 20.81 & 2.76 & 23.20 & 4.24 & 21.79 & 3.65 \\
\hline 2007 & 22.48 & 3.75 & 21.43 & 3.20 & 23.90 & 4.49 & 22.89 & 4.18 \\
\hline Change 1993-2000 & 0.64 & & 0.23 & & 1.23 & & 0.78 & \\
\hline Change 2000-2007 & 1.19 & & 0.72 & & 1.41 & & 1.15 & \\
\hline
\end{tabular}

Source: IFLS1, IFLS3, IFLS4

Note: Change signifies the average change in mean from 1993 to 2000 and from 2000 to 2007.

The lower part of Table 2 shows how BMI of individuals has changed over time, namely from 1993 to 2000 and from 2000 to 2007 . Mean change was positive in rural and urban areas and in both time periods. Furthermore, BMI change increased from the first to 
the second time period, suggesting that the nutrition transition in Indonesia has accelerated after 2000. The change was bigger for women than for men. Figure 1 visualizes the changes over time. It reveals that BMI distributions have become flatter between 1993 and 2007 for both men and women; that is, the population spread of BMI values has grown over time. In particular, the spread towards the right side of the distributions has increased, suggesting that individuals who started with higher BMI in 1993 increased their weight over-proportionally.

Figure 1: BMI density curves in 1993 and 2007

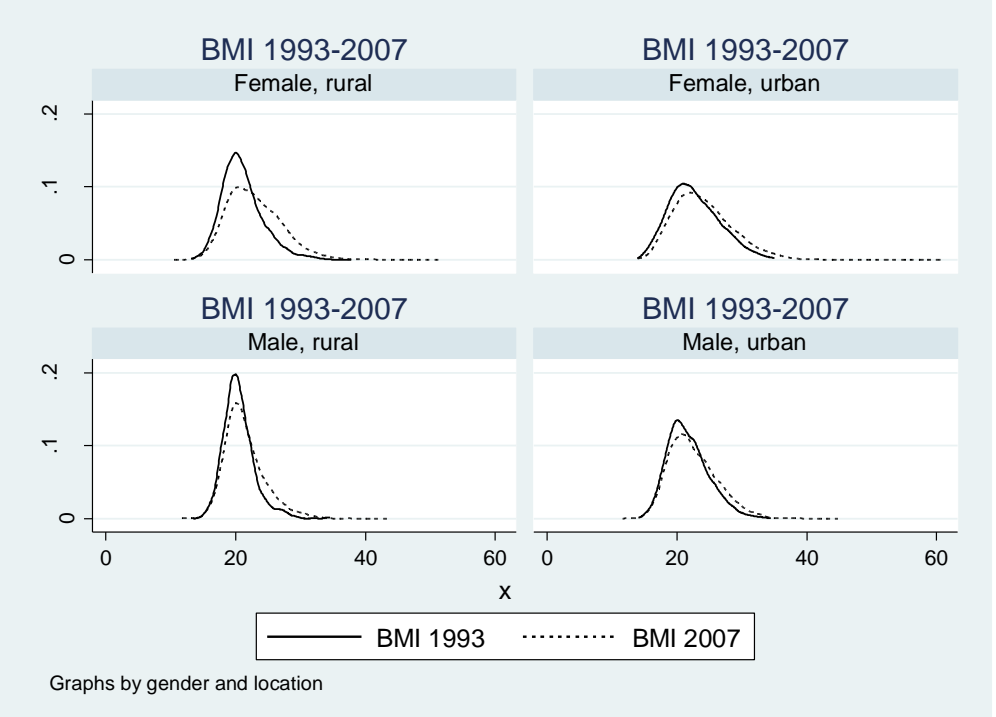

Source: IFLS 1, IFLS 4

In urban areas, where the nutrition transition usually starts, the BMI distributions are much flatter than in rural areas (Figure 1). Also, they are flatter for women than for men, which was true already in 1993. However, the most remarkable change between 1993 and 2007 is observed for women in rural areas, contradicting the widely held notion that the nutrition transition is confined to urban settings. In Indonesia, overweight and obesity are increasingly also becoming problems in rural areas. In Appendix 2 we show BMI distributions disaggregated by expenditure quintiles. The time trends discussed are clearly visible across all quintiles, underlining that also poorer population segments are increasingly affected by obesity. 
Figure 2 (panel A, using Asian cut-off values for BMI) shows that the share of preobese and obese adults in Indonesia has increased remarkably since 1993. At the same time, the share of underweight people has decreased, yet at lower pace, so that a declining proportion is classified as normal weight. This clearly illustrates that a dual burden of malnutrition is emerging in Indonesia, where undernutrition coexists with overnutrition. When international BMI cut-off values are used (panel B of Figure 2), obesity prevalence rates are lower, as expected, but the time trend is similar. As mentioned above, international BMI cut-offs seem to underestimate obesity problems in Asian populations, so that use of the lower Asian cut-offs is more appropriate.

Figure 2: Share of population in BMI categories over time (in \%)

Panel A: Asian cut-off values

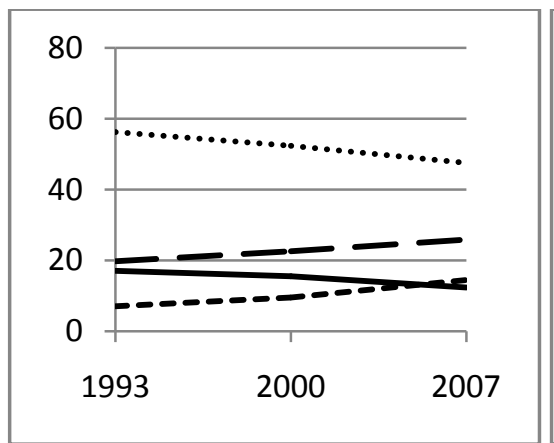

Source: IFLS1, IFLS3, IFLS4
Panel B: International cut-off values

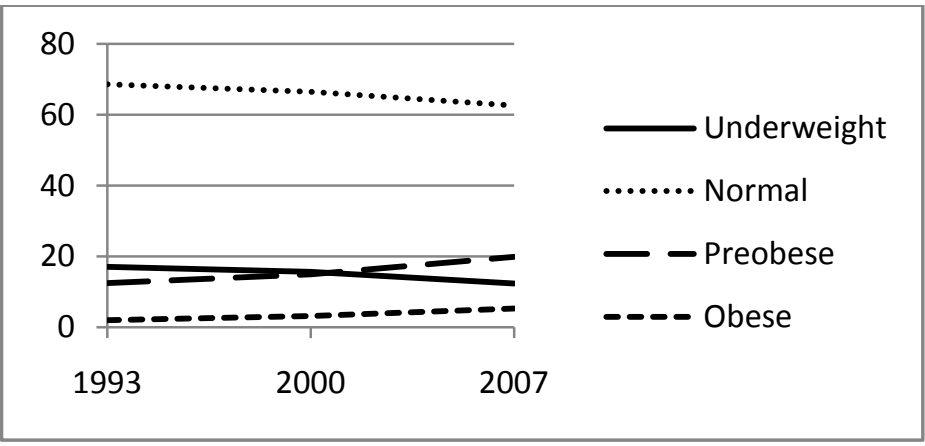

Table 3: Share of individuals in BMI categories (\%)

\begin{tabular}{lcccccc}
\hline & \multicolumn{2}{c}{$\mathbf{1 9 9 3}$} & \multicolumn{2}{c}{$\mathbf{2 0 0 0}$} & \multicolumn{2}{c}{$\mathbf{2 0 0 7}$} \\
\cline { 2 - 7 } & Male & Female & Male & Female & Male & Female \\
\hline $\begin{array}{l}\text { Underweight } \\
\text { Normal }\end{array}$ & 16.71 & 17.29 & 16.66 & 14.47 & 13.67 & 10.95 \\
weight & 62.45 & 50.71 & 58.78 & 45.91 & 54.95 & 40.31 \\
Preobese & 16.79 & 22.33 & 18.73 & 26.4 & 22.48 & 29.11 \\
Obese & 4.05 & 9.67 & 5.83 & 13.22 & 8.9 & 19.64 \\
Total & 100 & 100 & 100 & 100 & 100 & 100 \\
\hline Sourc: & & & & & & \\
\end{tabular}

Source: IFLS1, IFLS3, IFLS4

Note: Asian cut-off values were used for BMI categories.

Table 3 provides a breakdown of the trends by gender. While the prevalence of underweight is similar for men and women, this is not the case for the other BMI categories. Already in 1993, overweight rates were significantly higher for women than for men, and this trend continued over time. In 2007, about 50\% of all women were 
overweight; $20 \%$ were obese. In comparison, around $30 \%$ of the adult men in Indonesia are classified as overweight and less than $10 \%$ as obese. Higher obesity rates among women are in line with data from many other countries and can partly be explained by biological factors. Women seem to have a higher propensity to store fat. Furthermore, after pregnancy women often have the problem of losing excess weight that they gained. But there are also cultural factors, related to the type of work and leisure activities acceptable for women in certain societies (Hansford, 2010). Especially in countries with a high Muslim population, women are sometimes less free to do sports and other physical exercises, which may raise the likelihood of accumulating excess weight. As women are often responsible for food choices and allocation in the household, higher female obesity prevalence rates may also increase the risk of children becoming overweight.

Table 4: Food expenditures, household appliances, and television ownership by nutritional status $(1993,2000$, and 2007)

\begin{tabular}{|c|c|c|c|c|c|}
\hline \multirow[b]{2}{*}{ Variable } & \multicolumn{2}{|c|}{ Non-overweight } & \multicolumn{2}{|c|}{ Overweight } & \multirow{2}{*}{$\begin{array}{l}\text { Diff. in } \\
\text { means }\end{array}$} \\
\hline & Mean & Std. Dev. & Mean & Std. Dev. & \\
\hline $\begin{array}{l}\text { Food expenditures per capita (in } \\
100 \text { thsd. rupiah) }\end{array}$ & 1.563 & 1.830 & 2.101 & 2.211 & $* * *$ \\
\hline Meat and dairy share & 0.149 & 0.116 & 0.175 & 0.121 & $* * *$ \\
\hline $\begin{array}{l}\text { Staple food share } \\
\text { Household appliances (in } 100 \text { thsd. } \\
\text { rupiah) }\end{array}$ & 13.076 & 8.433 & 26.868 & 17.800 & $* * *$ \\
\hline Television & 0.651 & 0.477 & 0.811 & 0.391 & $* * *$ \\
\hline
\end{tabular}

We now turn to the association between BMI and behavioral variables. Table 4 compares food expenditures for overweight and non-overweight individuals. Total food expenditures are significantly higher for the overweight population. Likewise, the meat and dairy expenditure share is significantly higher for overweight people, while the share spent on traditional staple foods is significantly lower. These patterns are as expected; they indicate that BMI is closely correlated with changing diets in the nutrition transition. The 
lower part of Table 4 also confirms that the value of household appliances (e.g., washing machines, fridges, vacuum cleaners) and ownership of a television, which we use as proxies for lower physical activity during leisure time, are positively and significantly correlated with overweight. The association between work-related physical activity and BMI categories is shown in Figure 3. Individuals with sedentary jobs and those in housekeeping are more likely to be obese or preobese, whereas those who have higher physical activity levels in their work are more likely to be of normal weight or underweight.

Figure 3: Work-related physical activity and BMI category (1993, 2000, and 2007)

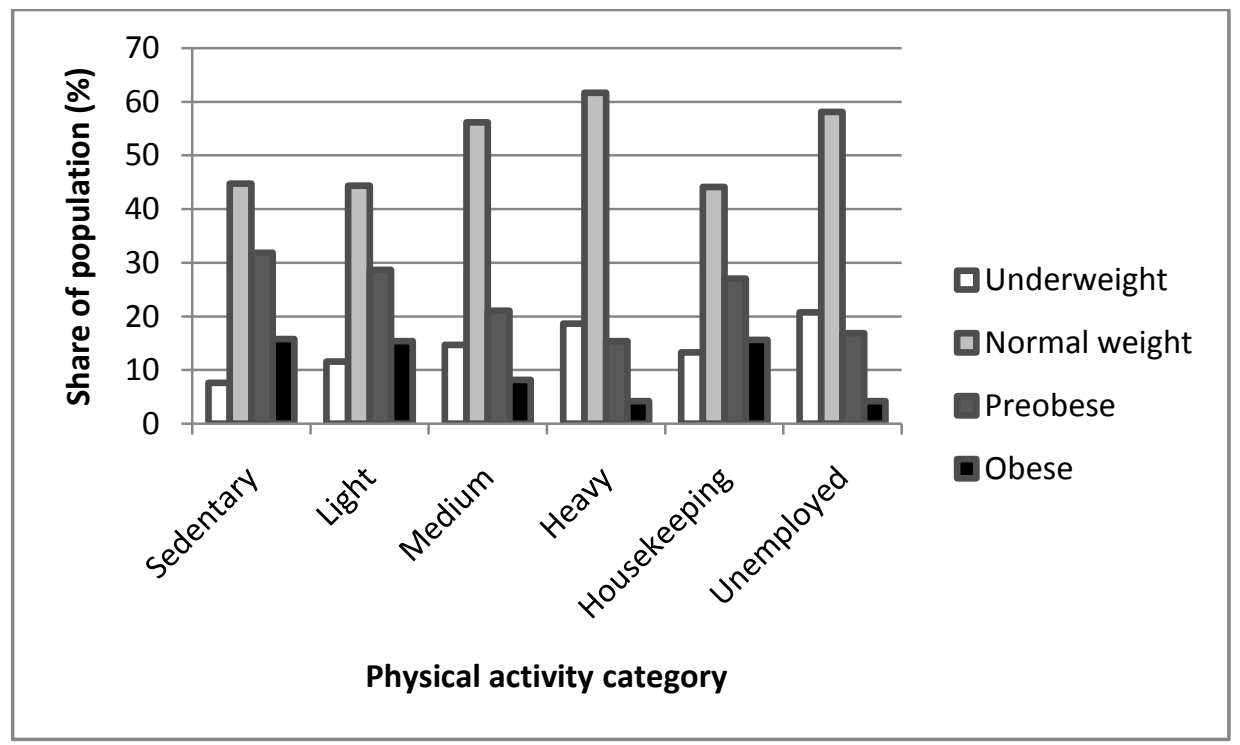

Source: IFLS1, IFLS3, IFLS4.

Note: Asian cut-off values were used for BMI categories.

\subsubsection{REGRESSION ANALYSIS}

The results of the panel regression models for BMI are shown in Table 5. Positive coefficients indicate that the particular factor tends to increase BMI, while negative coefficients imply a decreasing effect. As expected, higher living standards (measured in terms of per capita expenditure in 100 thsd. rupiah) contribute to higher BMI. The coefficients of the fixed effects models show that an expenditure increase by 100 thousand rupiah (which is a $25 \%$ increase over mean expenditure levels) raises BMI by 0.02 and 
0.03 among males and females, respectively. While these effects are highly significant, they are quite small, suggesting that there must be other important variables influencing nutritional outcomes. Education has a relatively strong positive effect on BMI for males but not for females. As educational levels of individuals at adult age hardly change over time, for this variable the random effects models provide more efficient estimates. Education is likely to increase nutritional awareness and health knowledge, so it should contribute to higher BMI for those at risk of underweight and to lower BMI for those at risk of overweight. Obesity rates in Indonesia are significantly higher among women; hence, the gender differences in education effects are plausible.

The random effects models show that rural location has a significantly negative effect on BMI for both males and females. This is probably related to higher physical activity levels in rural areas. While we control for work and leisure activities, these control variables do not fully account for infrastructure constraints in rural areas, which tend to increase walking and transportation distances and thus physical exercise. In contrast, being married has a large positive effect, significantly increasing the risk of overweight and obesity, especially for women. This is visible in both the fixed and random effects models. Interpreting the fixed effects coefficients, being married increases female BMI by 0.38 . This effect is likely due to cultural factors and changing lifestyles after marriage. Smoking reduces BMI significantly among men and women. 


\begin{tabular}{|c|c|c|c|c|c|c|c|c|}
\hline & \multicolumn{4}{|c|}{ Male } & \multicolumn{4}{|c|}{ Female } \\
\hline & \multicolumn{2}{|c|}{ Fixed effects } & \multicolumn{2}{|c|}{ Random effects } & \multicolumn{2}{|c|}{ Fixed effects } & \multicolumn{2}{|c|}{ Random effects } \\
\hline & Coefficients & $t$-statistics & Coefficients & $t$-statistics & Coefficients & $t$-statistics & Coefficients & $t$-statistics \\
\hline Constant & $19.42 * * *$ & $(24.49)$ & $18.95 * * *$ & $(115.5)$ & $20.96 * * *$ & $(20.27)$ & $19.32 * * *$ & $(84.29)$ \\
\hline Expenditures per capita & $0.0214 * *$ & $(2.331)$ & $0.0551 * * *$ & $(6.054)$ & $0.0279 * *$ & $(2.455)$ & $0.0431 * * *$ & $(4.704)$ \\
\hline Education & -0.0775 & $(-0.784)$ & $0.527 * * *$ & $(12.08)$ & -0.0599 & $(-0.463)$ & 0.0833 & $(1.637)$ \\
\hline Rural location & 0.0465 & $(0.510)$ & $-0.205^{* * *}$ & $(-3.874)$ & -0.0361 & $(-0.352)$ & $-0.488 * * *$ & $(-7.698)$ \\
\hline Married & $0.351 * * *$ & $(3.414)$ & $0.481 * * *$ & $(7.450)$ & $0.376 * * *$ & $(3.724)$ & $0.731 * * *$ & $(10.80)$ \\
\hline Smoking & $-0.255^{* * *}$ & $(-2.958)$ & $-0.614 * * *$ & $(-11.39)$ & 0.219 & $(0.987)$ & $-0.393 * *$ & $(-2.385)$ \\
\hline \multicolumn{9}{|l|}{ Food consumption } \\
\hline Food exp per capita. & $0.0366^{* *}$ & $(2.098)$ & 0.00123 & $(0.0733)$ & -0.00689 & $(-0.318)$ & -0.00446 & $(-0.240)$ \\
\hline Meat and dairy share & -0.155 & $(-0.709)$ & 0.226 & $(1.242)$ & -0.265 & $(-0.984)$ & 0.0418 & $(0.190)$ \\
\hline Staple food share & $-0.258 *$ & $(-1.682)$ & $-0.529 * * *$ & $(-4.142)$ & $-0.383 * *$ & $(-2.040)$ & $-0.622 * * *$ & $(-3.987)$ \\
\hline \multicolumn{9}{|c|}{ Work-related physical activity } \\
\hline Sedentary work & 0.101 & $(0.735)$ & $0.628 * * *$ & $(5.866)$ & $0.504 * *$ & $(2.359)$ & $0.662 * * *$ & $(4.145)$ \\
\hline Light work & $0.127 *$ & $(1.698)$ & $0.462 * * *$ & $(8.102)$ & $0.184^{*}$ & $(1.856)$ & $0.740 * * *$ & $(9.649)$ \\
\hline Medium work & $0.199 * * *$ & $(2.929)$ & $0.326 * * *$ & $(6.196)$ & 0.0600 & $(0.494)$ & $0.342 * * *$ & $(3.419)$ \\
\hline Housekeeping & -0.0623 & $(-0.469)$ & -0.0172 & $(-0.151)$ & 0.110 & $(1.376)$ & $0.564 * * *$ & $(8.688)$ \\
\hline Unemployed & $0.232 * *$ & $(2.032)$ & $0.312 * * *$ & $(3.702)$ & 0.467 & $(1.051)$ & $0.515^{*}$ & $(1.755)$ \\
\hline \multicolumn{9}{|c|}{ Leisure-related physical activity } \\
\hline Possession of television & 0.0387 & $(0.758)$ & $0.234 * * *$ & $(5.647)$ & 0.0516 & $(0.744)$ & $0.435 * * *$ & $(7.935)$ \\
\hline Household appliances & $8.16 \mathrm{e}-06$ & $(0.0103)$ & $0.00216 * * *$ & $(2.654)$ & $0.00243 * * *$ & $(2.918)$ & $0.00199 * * *$ & $(3.262)$ \\
\hline 2007 dummy & 0.356 & $(1.007)$ & $0.503 * * *$ & $(16.51)$ & $1.415^{* * *}$ & $(3.085)$ & $0.841 * * *$ & $(21.78)$ \\
\hline Observations & 18,138 & & 18,138 & & 19,378 & & 19,378 & \\
\hline R-squared & 0.237 & & & & 0.262 & & & \\
\hline Number of ID & 12,647 & & 12,647 & & 13,282 & & 13,282 & \\
\hline
\end{tabular}


The effects of behavioral variables are shown in the lower part of Table 5. Higher food expenditures contribute to higher BMI for males, as the fixed effects model indicates. Moreover, a higher expenditure share for traditional staple foods significantly reduces BMI in all models. This confirms the hypothesis that shifting away from traditional diets contributes to rising obesity. Yet, the other food-related variables are insignificant, which we mainly attribute to measurement problems. Aggregated food expenditure data seem to be weak proxies of calorie intake and dietary composition. This may be true in particular when using panel data from different time periods, where changes in food quality and prices are likely to occur.

Results for the physical activity proxies are in line with expectations. We mostly concentrate on the random effects coefficients, because data variation over time is very small for individuals. Lighter physical activity levels during work contribute to higher BMI. For instance, working in a sedentary job, as compared to a job involving heavy physical work, increases BMI by approximately 0.6 for men and women. The results also show that physical activity in leisure time has an important effect on BMI. Owning a television is associated with a 0.23 and 0.44 higher BMI for men and women, respectively, suggesting that watching television prevents people from more active hobbies. Furthermore, television may influence food consumption behavior through parallel intake of junk food and through commercial advertisements. Estimation coefficients for the value of household appliances are positive and significant, too, suggesting that these appliances ease physical activity during household work. The effects of the socioeconomic and behavioral variables are in addition to a general time trend that is captured by the 2007 dummy. Net of all other effects, BMIs in Indonesia were significantly higher in 2007 than in 2000 . 


\subsubsection{LIMITATIONS}

Our panel data analysis constitutes an improvement over most previous studies building on cross-section data, because we could include a broader set of socioeconomic and behavioral variables to explain BMI and could better account for time trends. Nonetheless, there are a few limitations, which are mostly related to data issues. First, per capita food expenditures are an imperfect proxy for individual level food consumption or intake, since important aspects such as food quality, waste, and intra-household distribution cannot be accounted for. Moreover, the aggregate food expenditure data available in the IFLS did not allow a more detailed analysis of sugar and fat contents or other aspects of dietary composition, which would have been interesting to better understand preference shifts and their nutritional implications. Second, issues of endogeneity in the regression analysis cannot be ruled out completely. While in the fixed effects models we control for unobserved heterogeneity, there may be potential problems of reverse causation. For instance, people with higher BMI may choose jobs or leisure time activities that are physically less strenuous. Such problems can be avoided through use of instrumental variables, as was recently done by $\mathrm{Ng}$ et al. (2010) in China. Unfortunately, price measures or other suitable variables that could be used as instruments for behavioral factors are not available in the IFLS.

To test the robustness of the results we tried different sets of variables in the regression analysis. When stepwise excluding food consumption, leisure activity, or workrelated variables, the remaining coefficients are mostly robust in terms of signs and significance levels. Some notable changes can be observed for living standard and education effects, but this is expected because these are correlated with behavioral factors. This correlation is also the reason why not including food consumption and physical 
activity levels may lead to estimation bias. In summary, better data would be useful for more accurate estimates, but our main findings seem to be fairly robust.

\subsection{DISCUSSION}

Our analysis of nutritional trends and determinants among adults confirms that Indonesia is in the process of a fast and profound nutrition transition, with constantly rising obesity rates. Comparing with other developing countries, Indonesian overweight rates in 1993 were similar to values observed in Brazil, China, and India at the same time. Also the rates observed in 2000 were similar to the ones in Brazil and China, but not to the ones in India anymore, since in India the nutrition transition has started much later (Jones-Smith et al., 2011b; Lu and Goldman, 2010; Subramanian et al., 2011). Even today, India still has high underweight rates and relatively low overweight rates (Gaiha et al., 2010). By contrast, in a few other middle income countries, such as South Africa, Mexico, Peru, or in transition countries such as Russia, the nutrition transition has started earlier than in Indonesia (Case and Menendez, 2009; Huffman and Rizov, 2010; Rivera et al., 2004).

The overweight problem in Indonesia is especially pronounced among females. Unlike often believed, rising obesity is not confined to urban and relatively richer households, but is increasingly observed also in rural areas and low income segments. This is in line with findings from a few other developing countries (Jones-Smith et al., 2011b). At the same time, underweight still persists in some pockets of Indonesia. The trends described here are similar to results based on the National Basic Health Survey (Riskesdas) of Indonesia, including prevalence rates when international cut-offs are used (Usfar and Fahmida, 2011; Usfar et al., 2010).

The fast increase in overweight and obesity prevalence rates in developing countries is probably supported by two mechanisms. First, there is a higher risk of overweight in stunted children (Fernald and Neufeld, 2006; Kimani-Murage et al., 2010; 
Popkin et al., 1996), and overweight in early years is a good predictor for overweight in adult age (Guo et al., 2002). Second, undernutrition in early childhood and fast weight gain increase the probability of chronic diseases and obesity (Kelishadi, 2007; Victora et al., 2008). Consequently, poverty and food insecurity are not only the main causes for undernutrition, but they indirectly also contribute to the obesity problem. This is especially true when incomes rise rapidly for some population groups, as is observed in Indonesia and many other developing countries.

Panel regressions have shown that changes in food consumption and physical activity levels are important determinants of BMI in Indonesia. Additional regressions, which were run to explain changes in BMI over time (results not shown), underline that individuals that are already overweight at a certain starting point tend to increase their BMI much more than individuals who start from normal weight. This clearly suggests that the obesity pandemic in Indonesia will further increase in extent and severity, unless significant remedial action is taken. A crucial precondition is that policymakers recognize obesity as a serious health and development issue.

Policy strategies need to raise awareness of the problem and its costs in terms of lost health and life quality. An important starting point is the use of BMI cut-off values for Asian populations in national health and nutrition statistics. Use of higher international cutoffs leads to underestimation of the obesity problem in Indonesia. To improve the situation, broad-based education campaigns towards more balanced diets and physical exercise should be considered, also clearly explaining the health risks associated with excess weight. Such campaigns need to have a long-term perspective, and they should already start in primary school. For obvious reasons, women should be targeted in particular, although cultural change certainly also requires the involvement of men. Workrelated physical activity will be difficult to influence through policy, because the trend 
towards more sedentary jobs is intrinsically linked with economic development. But the choice of transportation and leisure time activities may be influenced in the longer run.

Education and awareness campaigns may have to be accompanied by measures in the food industry to reduce the usage and consumption of sugar, fat, and salt. In addition to direct regulation of production and advertisement, food labels as well as taxes and subsidies to set incentives towards more healthy foods are options to be further analyzed. Experience from developed countries shows that such policies are sometimes difficult to implement and not always very effective. Tight cooperation between public and private sector entities will be important to instigate sustainable change.

There are also a few research implications emerging from our results. Cultural factors were not properly captured here, but they may be important to better understand nutritional trends and outcomes. Furthermore, the food expenditure data used are imperfect proxies of food consumption and dietary composition. This is a general problem in living standard survey data from developing countries. In order to better understand food preference changes in the nutrition transition, more disaggregated food consumption data are needed, including many more details on processed foods and meals eaten away from home. Availability of price data may help to further reduce possible issues of endogeneity. Databases and survey formats should be better adapted to emerging problems and research. 


\section{DUAL BURDEN HOUSEHOLDS AND NUTRITIONAL INEQUALITY IN INDONESIA}

\subsection{INTRODUCTION}

Currently, both underweight and overweight are challenges for policy-makers in developing countries. While undernutrition has long been a major concern, malnutrition in the form of overweight and obesity is a newly emerging issue. Countries in Latin America, North Africa and other regions have been dealing with the effects for years (Rivera et al., 2004), but recently we have seen this development in some Asian \& Sub-Sahara African countries (Jones-Smith et al., 2011a, 2011b; Martorell et al., 2000; Ziraba et al., 2009). China and India are the most prominent examples where overweight and obesity are new on the development agenda and chronic disease rates are rapidly increasing even though underweight is not yet eradicated (Khor, 2008). A process of changing food consumption and physical activity patterns caused by rising income levels, globalization and urbanization is contributing to this development termed the nutrition transition (e.g. Popkin, 2003; Popkin and Gordon-Larsen, 2004). Therefore, developing countries face a dual burden of nutrition in which the incidence of overweight is increasing, while the incidence of underweight is still a challenge. 
This dual burden phenomenon is not only found at the country level. At the household level, overweight and underweight can also coexist, where some members are overweight while others are underweight (e.g. Doak et al., 2005). This phenomenon has forced household economic theories to be revised. The unitary household model theory assuming equal distribution through equal preferences or a dictator making all allocation decisions was replaced by the theory of collective household models. These revised models help explain the unequal distribution of resources within the household due to parental preferences or bargaining frameworks (e.g., Alderman et al., 1995; Thomas, 1990).

Literature on the intra-household dual burden is characterized by several papers that categorize the household using the nutritional status of its members. For example, Doak et al. (2005) and Doak et al. (2000) find dual burden households in Brazil, China, Indonesia, Kyrgyz Republic, Russia, Vietnam and the United States. The relationship between this and income and urban location is one main research interest and differs across countries. For example in Indonesia and China "dual burden" and "overweight only" households are generally richer and located in urban areas; in other countries like Brazil and Russia, these households tend to have lower incomes (Doak et al., 2002; Doak et al., 2005).

Other studies calculate the mother-child dual burden comparing the nutritional status of the child with the nutritional status of the mother. Underweight children and overweight mothers are the most common paradox in all studies. Jehn and Brewis (2009) find that these pairs exist in mainly higher income and urban locations. A study of a Malay indigenous population by Saibul et al. (2009) finds that higher food variety in diets of dual burden households stands for a higher probability of overweight and obesity in adults. Khor and Sharif (2003) find in Malaysia mother-child pairs in which overweight mothers had relatively similar inputs but children showed illnesses and insufficient calorie consumption compared to children in normal weight pairs. When using the stunting measure for children, Garret and Ruel (2005) find high rates of dual burden households in 
countries where stunting in children is high or which are in the nutrition transition. Lee et al. (2010) and Lee at al. (2011) find for Guatemala that this dual burden is characteristic of the most disadvantaged -rural, poor and indigenous- population.

These measures described before have some drawbacks as the household categorization is relatively arbitrary. It does not take into account the magnitude of the intra-household inequality and the analysis of mother-child pairs only uses limited information within the household. An improved measure of nutritional inequality is the continuous measure used by Sahn and Younger (2009). They used the Body Mass Index (BMI) of all household members and calculate the intra-household nutritional Theil index. In their study higher intra-household health inequality is associated with higher well-being and higher mean BMI (Sahn and Younger, 2009). Using the Theil index at the household level allows a more precise measure of intra-household nutritional inequality and allows households to be ranked in a more reliable way. This is the only published study using the nutritional Theil index at the household level.

Building upon their work, we introduce this measure into our analysis of dual burden households. We conduct a detailed analysis of trends and determinants of nutrition using a large-scale panel household survey using the categorization of Doak et al. (2005) and the nutritional Theil index from Sahn and Younger (2009). In addition to the novelty of using the Theil index, panel data has not yet been used in this field. Our goal is to provide more information about the dynamics and determinants of intra-household nutritional inequality in developing countries to provide insights for policy development. We stress the importance of our descriptive analysis in terms of wealth, the nutrition transition and household head characteristics, and what that can mean for policy options. In particular, female decision-making appears crucial for the support of child and family health (e.g. Hoddinott and Haddad, 1995; Thomas, 1990). Our regression analyses help 
control for several coexisting influences and for unobserved heterogeneity in a panel framework.

For our analysis, we rely upon data from Indonesia which is one of the most populous developing country. Indonesia shows increasing incomes and is in the middle of the nutrition transition (Roemling and Qaim, 2012). Food consumption and physical activity patterns are changing. Energy intake is increasing and micronutrient deficiency is decreasing (Kurniawan, 2002). Underweight rates for adults and stunting rates for children are going down but rates of overweight and obesity are increasing. However, undernutrition is still prevalent and a dual burden of nutrition at the country level is evident and has been found at the household level by Doak et al. (2005).

The paper is structured as follows. In the next section, we describe our data and the empirical approach. In section three, we present the results and discussion. The final section provides conclusions and policy implications.

\subsection{DATA AND METHODS}

\subsubsection{DATA}

This study uses the Indonesian Family and Life Survey (IFLS) that encompasses four survey waves from 1993, 1997, 2000, and 2007 (Frankenberg and Karoly, 1995; Frankenberg and Thomas, 2000; Strauss et al., 2004; Strauss et al., 2009). The data are representative for 83 percent of the Indonesian population (13 out of 27 provinces). The selection of the provinces was done taking account of the high heterogeneity of the population, and included the following: North Sumatra, West Sumatra, South Sumatra, and Lampung (in Sumatra), DKI Jakarta, West Java, Central Java, DI Yogyakarta, and East Java (in Java), as well as Bali, West Nusa Tenggara, South Kalimantan, and South Sulawesi. Villages and households were sampled using the National Socioeconomic 
Survey (SUSENAS) sampling frame of the Indonesian Bureau of Statistics (BPS). Further information on the sampling scheme and additional information is given in Frankenberg and Karoly (1995), Frankenberg and Thomas (2000), Strauss et al. (2004) and Strauss et al. (2009).

In the first wave of the survey, not all household members were interviewed in the original households. After the first wave of 1993, all household members in the original households were interviewed. Thus, in the first wave, results can differ because of this difference in sampling scheme. In particular, the 15 to 25 year age group has a relatively low population share in the first wave. Still, when we compare results of this age group over the years, results seem plausible and not biased within or by this group.

\subsubsection{MEASURES OF NUTRITIONAL INEQUALITY}

\subsubsection{THE BMI}

As mentioned previously, we use two measurements (a categorization of households and the intra-household nutritional Theil index) to assess and analyze the within-household dual burden and intra-household nutritional inequality. The basis for both measurements is the anthropometric measure Body Mass Index (BMI), calculated by dividing the weight in kilograms by the squared height in meters. The measurement offers an individual-level measurement of health and nutrition and is widely recognized as an accurate measurement of nutritional outcomes (WHO, 1995, 2000). We use the standardized BMI-for-age for children and adolescents to make it comparable across different age groups and genders. For the standardization, optimal growth curves have been calculated for children and adolescents that set a comparable standard in every month of life until the age of 19 years (WHO, 1995). In the newest version of this standardization, children from different ethnic groups are included in the reference groups to account for possible differences across populations (de Onis et al., 2007; WHO, 2009). 


\subsubsection{DUAL BURDEN HOUSEHOLDS}

Our first measure for intra-household inequality is the categorization of households into four categories: underweight, normal weight, overweight and dual burden (Doak et al., 2002; Doak et al., 2005; Doak et al., 2000; Doak et al., 1999). This categorization uses the nutritional status of the individual. For adults the recommended cut-off values of the BMI for overweight and underweight by the WHO are used (WHO, 1995). They need to be adapted for Asian populations since they have a higher risk of morbidity at lower levels of body fat and BMI than other ethnic groups (Deurenberg et al., 2002; Gurrici et al., 1998; WHO, 2004). For adults, a BMI of higher than 23 is categorized as overweight rather than the average of 25 across all populations. However, the cut-off value 18.5 for underweight is as in other populations (WHO, 1995).

The BMI-for-age has also for children and adolescents been proved to be a good indicator for overweight, obesity and also underweight (Cole et al., 2007; Mei et al., 2002). Only the method used to classify weight status is different and for comparability needs to be adjusted for age and gender since body composition changes rapidly during childhood and adolescence. The BMI-for-age is constructed by calculating optimal growth curves that account for age and gender. These are used to derive percentiles of BMI that stand for higher morbidity and mortality from undernutrition or overweight. Measurements of BMI for children and adolescents can with these growth curves and other parameters (the median, the Box-Cox transformation parameter and the coefficient of variation of the reference population) be standardized into z-scores to achieve comparability across the different groups. Zero represents the optimal z-score and certain standard deviations are associated with underweight or overweight. Underweight with the BMI-for-age measure has been defined as a standard deviation of minus two and overweight as a standard deviation of plus one (de Onis, 2010; WHO, 2012). 
This categorization of the individuals is then used to classify the household where a normal weight household consists of only normal weight members. An underweighthousehold has at least one underweight member and a variable number of normal weight members. The overweight household has at least one overweight member apart from normal weight members. The dual burden household has at least one underweight and one overweight individual while the rest of the members can be of normal weight.

\subsubsection{INTRA-HOUSEHOLD NUTRITIONAL THEIL INDEX}

As mentioned, our second measure calculates the intra-household nutritional Theil index using the BMI of the members (Araar et al., 2009; Sahn and Younger, 2009). As continuous measurement for intra-household nutritional and health inequality, it helps to eliminate the problem of inappropriate categorization due to arbitrary cut-offs and high heterogeneity within groups. Further, it provides the opportunity to measure the distance between household members, giving a more precise measurement of inequality. We standardize the BMI for all individuals to calculate the Theil inequality index at the household level with the same method used by Sahn and Younger (2009). The standardization is conducted using the following formula to standardize and solve for the BMI.

Thus from

$$
\text { (1) } \quad \mathrm{z}=\frac{\left((\mathrm{BMI} / \mathrm{m})^{1}-1\right)}{(1 * \mathrm{~s})} \text {, }
$$

we derive

$$
\text { (2) } \quad \mathrm{BMI}=\mathrm{m}(\mathrm{z} * \mathrm{l} * \mathrm{~s}+1)^{\frac{1}{1}} \text {, }
$$

where $\mathrm{m}, 1$ and $\mathrm{s}$ are the median, the Box-Cox transformation parameter and the coefficient of variation of the reference population, respectively, in this case a 20 year old female (WHO, 2009). Once all z-scores are converted into BMIs, we calculate the household-level $(\mathrm{H})$ Theil index of intra-household inequality. 


$$
\text { (3) } \mathrm{T}_{\mathrm{H}}=\frac{1}{\mathrm{~N}} \sum_{\mathrm{i}=1}^{\mathrm{N}}\left(\frac{\mathrm{BMI}_{\mathrm{i}}}{\overline{\mathrm{BMI}}} * \ln \left(\frac{\mathrm{BMI}_{\mathrm{i}}}{\overline{\mathrm{BMI}}}\right)\right)
$$

$\mathrm{BMI}_{\mathrm{i}}$ is the individual's BMI value, $\overline{\overline{\mathrm{BMI}}}$ is the mean BMI of the household and $\mathrm{N}$ is the number of household members.

\subsubsection{COVARIATES}

Several factors could be thought of as likely determinants of intra-household nutritional allocation and resulting inequality, such as the distribution of food, physical activity, and healthcare. Of course, this is dependent upon the availability of this goods and the decision-making within the household. Since data on the within-household distribution of these factors is not available, we use general determinants such as income, education, location, household head characteristics and household composition as proxies for intrahousehold allocation of food and healthcare. In particular, we investigate the connection between intra-household nutritional inequality and wealth indicators. Expenditures are measured as total expenditure levels per capita for consumption of all food and non-food goods and services. For the descriptive analysis, we also present expenditure quintiles.

General characteristics such as urban/rural location and province and household characteristics such as mean household age, household size, and the number of children and working household members are important factors to consider. In the regression, dummy variables were included to control for rural areas and provinces. The mean household age was calculated by summing the age of all household members divided by the household size. The household size counts total members, the number of children all children and adolescents under 19 years old and the number of working household members all members that stated that they have worked in the last week.

Of course, it is important to consider the characteristics of the household head as they are crucial for purchase and distribution of food and healthcare. In particular, the age, 
education, occupation and gender of the household head can be important influencing factors. Education levels are defined as "no education", "primary school", "secondary school" and "tertiary education". The occupation type can be an important factor since the household head's occupation can create time constraints for food preparation and planning but also for food needs and occupational choices of other members. The occupation of the household head is categorized by occupation codes (sedentary work, light work, medium work, heavy work, housekeeping, unemployed and retired). Age of the household head is measured continuously and the gender of the household head is a dummy variable where 1 identifies a female household head.

\subsubsection{STATISTICAL ANALYSIS}

In our analysis, we focus first on the descriptive investigation of different household categories and intra-household nutritional inequality, using the measures described above, analyzing correlations and associations with possible determinants. Building on this knowledge of the household descriptives, we conduct regression analyses to look at the determinants of nutritional inequality.

For the categorical household classification, we apply probit regressions with random effects, comparing the dual burden household with other parts of the sample population. First, we compare the dual burden household with all other households, then with normal weight and underweight households combined and lastly, we compare them with overweight households, calculating marginal effects of the determinants. We use random effects estimation since equal outcomes over time would be dropped from the sample in a fixed-effects panel probit estimation. While this has the strong assumption of no correlation between the individual part of the error term and the independent variables, it is the best option for our data. Within a multinomial panel framework we were not able to achieve convergence. 
In a second step, we use the continuous measure of household inequality and conduct fixed effect and random effect panel estimation. Fixed effect regressions are consistent since they do not rely on the non-correlation of the error term and the independent variables. The Hausman test finds significant differences between the two models, supporting the use of the fixed effect model. However, since random effect models have the advantage of efficiently estimating the time-invariant and almost time-invariant variables like education or occupation, we show these results as well.

For the analysis, the Theil index is log-transformed to improve statistical properties and interpretation. The independent variables are the same in all specifications. Time dummies are included in the regression analysis to account for time fixed effects not captured by the covariates. Robust and cluster-adjusted standard errors at the household level have been used in the Theil regressions.

\subsection{RESULTS}

\subsubsection{TIME TRENDS AND PREVALENCE RATES}

The data show that intra-household inequality is a problem for Indonesian households. Dual burden households have a stable share of around 17 percent of all households from 1997 to 2007 (Table 6). This number increased from 1993 levels by about 5 percentage points. However, the share of underweight households declines steadily from 1993 to 2007 with a significant decline after 2000, with only 15 percent of households currently underweight. This clearly shows an improvement of the nutritional conditions in Indonesia at the household level. Interestingly, however, the category showing the largest change is the category of overweight households. In 2007, 50 percent of all households are categorized as overweight compared to only 35 percent in 1993. 
Table 6: Household categories of nutritional outcome

\begin{tabular}{lcccccccc}
\hline & $\mathbf{1 9 9 3}$ & $\mathbf{\%}$ & $\mathbf{1 9 9 7}$ & $\mathbf{\%}$ & $\mathbf{2 0 0 0}$ & $\mathbf{\%}$ & $\mathbf{2 0 0 7}$ & $\mathbf{\%}$ \\
\hline Underweight & 1,359 & 26.34 & 1,347 & 23.76 & 1,587 & 21.30 & 1,351 & 14.94 \\
Normal & 1,364 & 26.44 & 1,167 & 20.59 & 1,414 & 18.98 & 1,556 & 17.21 \\
Dual burden & 621 & 12.04 & 977 & 17.24 & 1,377 & 18.48 & 1,546 & 17.1 \\
Overweight & 1,815 & 35.18 & 2,177 & 38.41 & 3,073 & 41.24 & 4,587 & 50.74 \\
Total & 5,159 & 100 & 5,668 & 100 & 7,451 & 100 & 9,040 & 100 \\
\hline Source: IFLS1, IFLS2, IFLS3, IFLS4 & & & & & & &
\end{tabular}

The Theil index shows a different picture and gradually increases over time in each year (Table 7). While rates are relatively higher in urban areas, rates have increased in both rural and urban locations over time. Therefore, despite the decrease in underweight, the Theil index shows a clear increase over time in dual burden households since the spread in BMI is increasing. This confirms the general results found in Roemling and Qaim (2012) that the BMI distribution is widening in Indonesia.

Comparing our two measures, the intra-household Theil index shows highest intrahousehold inequality in dual burden households (Figure 4). However, overweight households also have relatively high values of nutritional inequality at the household level. Therefore, even for overweight households, more than one targeting food and health policy may be appropriate.

Table 7: Nutritional Theil index at household level over time and rural/urban location

\begin{tabular}{lccc} 
& total & rural & urban \\
\hline $\mathbf{1 9 9 3}$ & 0.0074 & 0.0063 & 0.0087 \\
$\mathbf{1 9 9 7}$ & 0.0084 & 0.0074 & 0.0096 \\
$\mathbf{2 0 0 0}$ & 0.0088 & 0.0077 & 0.0102 \\
$\mathbf{2 0 0 7}$ & 0.0099 & 0.0090 & 0.0109 \\
\hline Source: IFLS1, IFL S2 IFLS3, IFLS4
\end{tabular}

The transition matrix in Table 8 shows changes over time in the household categorization and reveals the directions of change. For example, 50 percent of those categorized as underweight are also classified as underweight in the next period. The other half of underweight households transitions into other categories. Over 60 percent of 
households categorized as normal weight or dual burden are in a different category the next period. Even though the general share of the population categorized as underweight has been reduced, there is still high nutritional vulnerability in Indonesia. Dual burden households tend to be transitional households in that members become mostly of normal weight or overweight.

Figure 4: Intra-household nutritional Theil index over time and household BMI category

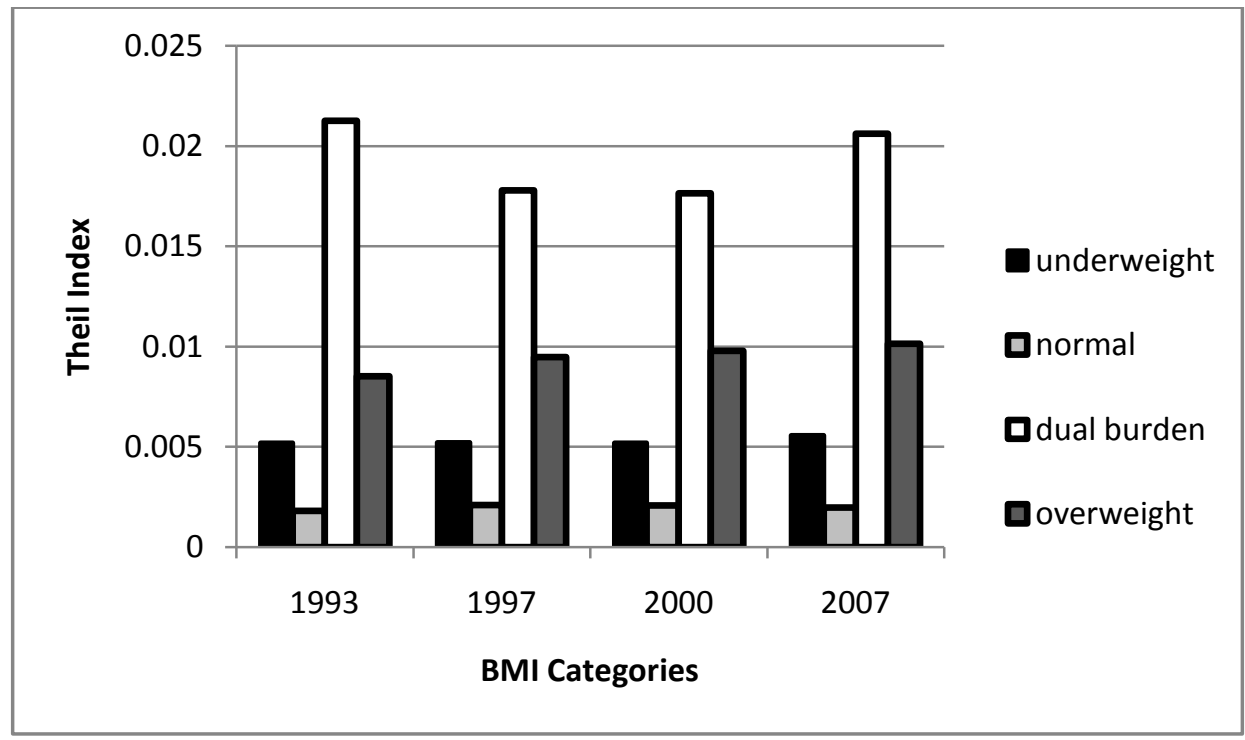

Source: IFLS1, IFLS2, IFLS3, IFLS4

Thus, in contrast to the findings of Jehn and Brewis (2009), we see the dual burden as a transitory phenomenon since households in our case move in and out of this category. Households classified as overweight tend to be the most static, with 70 percent of households classified as overweight in one period also classified as overweight in the next period. This is quite alarming since overweight and obesity is becoming more and more of a problem in Asian developing countries. This trend is very hard to reverse.

Table 8: Transition matrix: Transition over time between the BMI household categories

\begin{tabular}{lccccc}
\hline & Underweight & Normal & Dual burden & Overweight & Total \\
\hline Underweight & 50.94 & 17.73 & 17.41 & 13.91 & 100 \\
Normal & 18.71 & 38.18 & 9.54 & 33.58 & 100 \\
Dual burden & 11.8 & 7.01 & 43.52 & 37.66 & 100 \\
Overweight & 3.65 & 8.1 & 15.22 & 73.03 & 100 \\
Total & 19.37 & 16.78 & 19.08 & 44.77 & 100 \\
\hline
\end{tabular}

Source: IFLS1, IFLS2, IFLS3, IFLS4 
Table 9: Mean number of underweight and overweight household members by age group and BMI household category

\begin{tabular}{|c|c|c|c|c|c|c|}
\hline \multirow[b]{2}{*}{ Age group } & \multicolumn{2}{|c|}{ Dual burden $(n=4521)$} & \multicolumn{2}{|c|}{ Overweight $(n=11652)$} & \multicolumn{2}{|c|}{ Underweight $(n=5644)$} \\
\hline & Mean & Std. Dev. & Mean & Std. Dev. & Mean & Std. Dev. \\
\hline \multicolumn{7}{|c|}{ Underweight } \\
\hline till 10 & 0.225 & 0.454 & 0 & 0 & 0.178 & 0.425 \\
\hline 10 to 20 & 0.218 & 0.453 & 0 & 0 & 0.177 & 0.430 \\
\hline 20 to 30 & 0.273 & 0.508 & 0 & 0 & 0.250 & 0.487 \\
\hline 30 to 40 & 0.137 & 0.350 & 0 & 0 & 0.181 & 0.407 \\
\hline 40 to 50 & 0.100 & 0.302 & 0 & 0 & 0.144 & 0.373 \\
\hline 50 to 60 & 0.111 & 0.320 & 0 & 0 & 0.184 & 0.418 \\
\hline 60 to 70 & 0.115 & 0.327 & 0 & 0 & 0.176 & 0.406 \\
\hline over 70 & 0.098 & 0.304 & 0 & 0 & 0.136 & 0.372 \\
\hline \multicolumn{7}{|l|}{ Overweight } \\
\hline till 10 & 0.132 & 0.363 & 0.144 & 0.379 & 0 & 0 \\
\hline 10 to 20 & 0.073 & 0.283 & 0.106 & 0.339 & 0 & 0 \\
\hline 20 to 30 & 0.206 & 0.437 & 0.247 & 0.485 & 0 & 0 \\
\hline 30 to 40 & 0.329 & 0.526 & 0.434 & 0.600 & 0 & 0 \\
\hline 40 to 50 & 0.313 & 0.523 & 0.350 & 0.571 & 0 & 0 \\
\hline 50 to 60 & 0.189 & 0.418 & 0.189 & 0.439 & 0 & 0 \\
\hline 60 to 70 & 0.077 & 0.278 & 0.090 & 0.309 & 0 & 0 \\
\hline over 70 & 0.031 & 0.175 & 0.037 & 0.197 & 0 & 0 \\
\hline
\end{tabular}

Source: IFLS1, IFLS2, IFLS3, IFLS4

Note: Pooled sample is used.

As long as underweight exists, dual burden households will continue being a problem in developing countries, especially since obesity generally increases with age while undernutrition is more prevalent in children. This is the case especially in dual burden households as shown in Table 9. Underweight in dual burden households is mainly seen in children, while overweight is highest in the middle age categories between 30 and 50 years old. In contrast, in underweight households, the underweight members are equally distributed over all age groups. Overweight households show higher overweight rates for individual members than dual burden households in most age categories.

We also look at the statistics by gender and because of space constraints only summarize the results. For adults, overweight is more common in females and underweight is more common in males. In overweight households, girls are also generally more overweight than boys. In purely underweight households, these differences between 
genders is not as strong, but in the group between 40 and 60 , females have a higher average of underweight members than males.

From these descriptive results, we deduce that inequality in nutritional outcomes in our data is rather unintentional inequality. With intentionally unequal resource allocation, we would expect the preference of males over females, income earners over non-income earners or children over adults. But for all this we do not see a clear support. Male are rather underweight and children as well. Therefore, inequality seems rather unintended and has its reasons probably in bad quality of food or healthcare and lacking health and nutrition knowledge.

\subsubsection{DESCRIPTIVE ANALYSIS OF SOCIOECONOMIC FACTORS}

Now we further analyze the determinants of this problem. First, we compare BMI categories of the household with expenditure quintiles (Figure 5, Panel 1). The pattern is that dual burden households are distributed rather equally over different quintiles whereas overweight households are relatively richer and underweight households relatively poorer than normal weight households. However, this impression changes when we look at each year of the survey separately. In the first year, dual burden households have the highest share in the highest quintile with over 25 percent are in the fifth quintile and only 15 percent are in the lowest quintile. Over time this changes, so that in 2007 , the lowest quintile has the highest share and the highest quintile the lowest share of dual burden households.

With expenditure, one has to take into account that underweight is often an issue of the poor while overweight is generally a problem of the rich. Therefore, the probability of both coexisting should be highest in the middle income segments but we do not see this in our data. That is because in Indonesia the nutrition transition is processing and while overweight is already a problem of the poor; the rich get less and less underweight. This 
leads to higher inequality for the lowest quintile in 2007. The Theil index in contrast increases with higher quintile and differences between quintiles decrease over the years, equalizing levels across the expenditure quintiles.

Figure 5: Household BMI categories by expenditure quintile

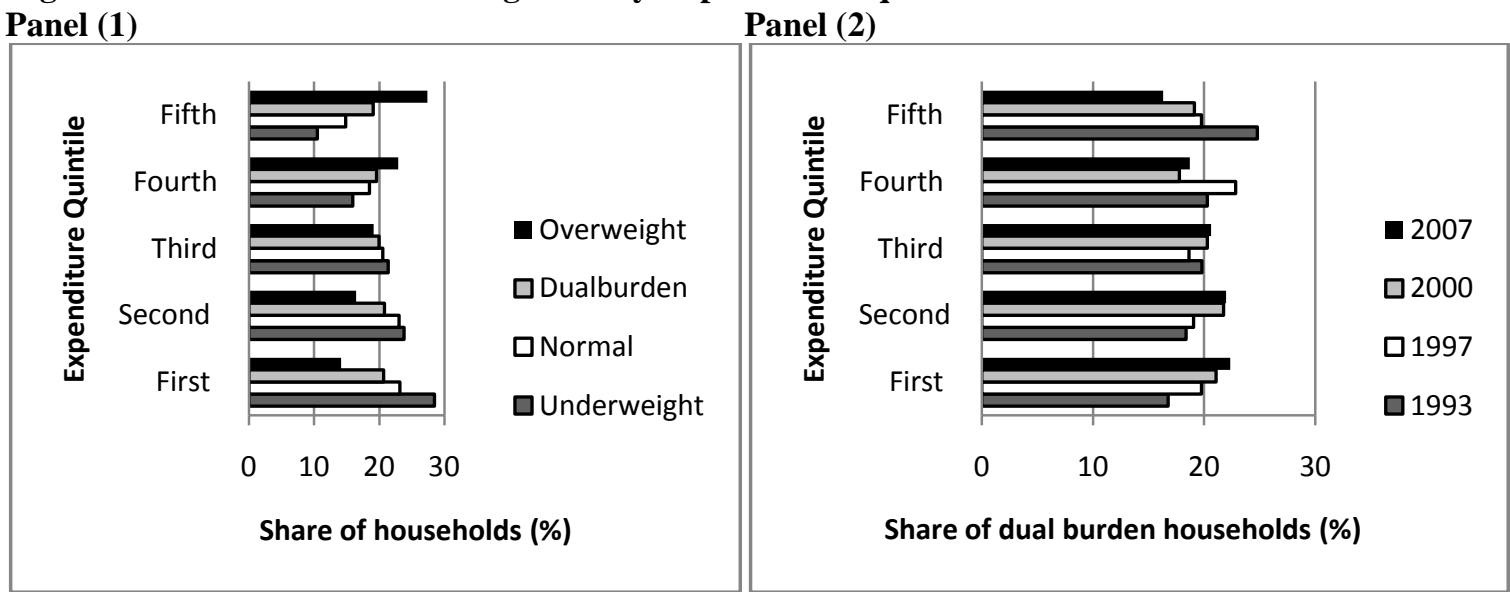

Source: IFLS1, IFLS2, IFLS3, IFLS4

Note: Panel (1) is the pooled sample across expenditure quintiles. Panel (2) is only the dual burden households across expenditure quintile over time. Differences are significant across household BMI categories.

Possible explanations of a higher inequality with higher expenditure are difficult to find but Sahn and Younger (2009) also find a positive association with well-being and intra-household health inequality. One possibility is that the richer households do not have problems in providing food but having good quality healthcare may still be a problem. For children this has also been detected to be very important since they are more vulnerable to diseases (Khor and Sharif, 2003; Molini et al., 2010). Indonesian households have also been shown to be very vulnerable with respect to healthcare since during the Asian financial crisis health expenditures went rapidly down because healthcare is mainly paid privately (Waters et al., 2003). In general, the healthcare system in Indonesia lacks sufficient coverage and quality, even though progress has been made in recent years and programs especially insuring the poor like Askeskin are valuable (Rokx et al., 2009).

Urbanization is another important factor often associated with the dual burden problem. Also in our study, the Theil index shows higher inequality in urban areas than in rural areas. Furthermore, only around 45 percent of the dual burden and overweight 
households are located in rural areas but about 65 percent of the normal and underweight households are located there. This has consequences for the kind of job available to the household head. A lower share of heavy workers can be found in dual burden as well as overweight household categories. Inequality is also higher when the household head has a low physical activity occupation.

In general, urbanization provides many new opportunities in food choice, work choice and reduced physical activity which may support the dual burden syndrome. Thus, Indonesian dual burden households are similar to overweight households confirming the result of Doak et al. (2005). However, over time, dual burden households have the highest share in the lowest expenditure quintile moving in the direction of Brazil and Russia (Doak et al., 2005). This further supports the transitory nature of dual burden households.

Table 10: Theil index and nutrition transition characteristics

\begin{tabular}{lccccc}
\hline & Theil index & Observations & Mean & Std. error & Significance \\
\hline Rice share in total food & low & 13659 & 0.060 & 0.053 & $* * *$ \\
expenditure & high & 13656 & 0.046 & 0.043 & $*$ * \\
Meat and dairy share in total & low & 13659 & 0.151 & 0.117 & $* .119$ \\
food expenditure & high & 13656 & 0.168 & 0.490 & $* *$ \\
Television possession & low & 11075 & 0.600 & 0.444 & \\
\hline
\end{tabular}

Source: IFLS1, IFLS2, IFLS3, IFLS4

Note: Theil index divided at the median into low and high Theil index. Information about television possession is for 1993 not available. Significance stands for significant different between low and high level Theil index for each variable.

Further similarities between overweight and dual burden households not shown in the tables confirm these households to be characterized by the nutrition transition. Both overweight and dual burden households have significantly higher shares of television possession, lower share of rice in their food expenditure and a higher share of meat and dairy products in the food expenditures, even after controlling for income. The Theil index can provide characteristics of inequality in the different household categories. We see that higher inequality in overweight households is associated with a lower share of rice in total food expenditures, higher share of meat and dairy food expenditure, more urban locales 
and the higher rates of television possession (Table 10). Therefore, characteristics associated with the nutrition transition are also factors for higher intra-household inequality within overweight households.

Characteristics of household composition show that the number of household members, the number of children and the number of working household members is highest in dual burden households. These three characteristics show the high vulnerability for malnutrition. Children are more vulnerable than adults for undernutrition and many working household members create time constraints in caring for children by providing good quality food. In general, large households can create difficulties in ensuring equal distribution.

A female household head or resources in the hands of women often makes a difference. In this survey about 13 percent of all households are headed by females (Appendix 3). Female household heads show lower shares in overweight and dual burden households than men. Excluding 1993, a female household head is significantly and negatively associated with the Theil index (Table 11). Thus, in a household with a female household head, the intra-household inequality is generally lower (not controlling for other factors). The share of female-headed households in overweight households is also lower. From the higher prevalence rates of overweight in women, one would expect the contrary.

Table 11: Intra-household nutritional inequality and gender of household head

\begin{tabular}{llcccc}
\hline & Household head & Observations & Mean & Std. error & Significance \\
\hline Dual burden household & male & 23844 & 0.169 & 0.375 & $* * *$ \\
& female & 3474 & 0.142 & 0.349 & \\
\multirow{2}{*}{ Overweight household } & male & 23844 & 0.432 & 0.495 & $* * *$ \\
& female & 3474 & 0.386 & 0.487 & $*$ \\
Theil index & male & 23844 & 0.0089 & 0.0104 & $*$ \\
& female & 3474 & 0.0085 & 0.0103 & \\
\hline
\end{tabular}

Source: IFLS1, IFLS2, IFLS3, IFLS4

A straightforward explanation would be a lower income for these households but the income levels appear to be similar to male-headed households. However, male-headed 
households show more of the characteristics associated with the nutrition transition, such as a lower share of television possession and a lower share of rice in the food expenditure when compared to female household heads.

\subsubsection{REGRESSION ANALYSIS}

In our regression analysis, we are able to control for all these variables that may influence inequality as noticed in the descriptive data. The probit regressions show that education of the household head increases the probability of being a dual burden household in comparison to the reference group of normal weight and underweight households (Table 12, column 2). This shows that education is not equal nutrition and health knowledge and that this needs to be addressed separately. The occupational variables are mostly not significant determinants but having physical work does decrease the probability of being in the dual burden category. Higher exercise is associated with a lower probability of overweight, thus probably balancing out the excess calorie input. Female household heads and younger household heads also significantly diminish the probability of being a dual burden household. Expenditures, household size, and the number of working household members all increase the probability of being a dual burden household, while rural location reduces the probability. The time dummies are all positive and increasing over time. 
Table 12: Panel random effects probit estimation for household categories (marginal effects)

(1)

Dual burden

\begin{tabular}{|c|c|c|c|c|c|c|}
\hline Primary school & 0.00832 & $(1.093)$ & $0.0366 * *$ & $(2.341)$ & -0.0234 & $(-1.353)$ \\
\hline Secondary school & $0.0167 *$ & (1.809) & $0.0848 * * *$ & $(3.982)$ & -0.0204 & $(-1.056)$ \\
\hline Tertiary education & 0.00364 & (0.299) & $0.155^{* * *}$ & (3.977) & $-0.0549 * *$ & $(-2.551)$ \\
\hline Light work & 0.00150 & $(0.151)$ & 0.00355 & $(0.144)$ & 0.000899 & $(0.0467)$ \\
\hline Medium work & 0.00232 & $(0.225)$ & -0.0275 & $(-1.162)$ & 0.0246 & $(1.180)$ \\
\hline Heavy work & $-0.0299 * * *$ & $(-3.044)$ & $-0.104 * * *$ & $(-4.414)$ & -0.0159 & $(-0.767)$ \\
\hline Housekeeping & 0.00592 & $(0.423)$ & -0.0245 & $(-0.857)$ & 0.0402 & $(1.332)$ \\
\hline Unemployed & 0.0284 & (1.494) & -0.00735 & $(-0.212)$ & $0.0995 * *$ & $(2.450)$ \\
\hline Retired & 0.0221 & $(1.472)$ & 0.00106 & $(0.0338)$ & $0.0697 * *$ & $(2.294)$ \\
\hline $\begin{array}{l}\text { Female household } \\
\text { head }\end{array}$ & $-0.0170 * *$ & $(-2.438)$ & $-0.0483 * * *$ & $(-3.390)$ & -0.0213 & $(-1.336)$ \\
\hline $\begin{array}{l}\text { Age of household } \\
\text { head }\end{array}$ & $0.00164 * * *$ & $(6.298)$ & $0.00450 * * *$ & $(8.105)$ & $0.00271 * * *$ & $(4.754)$ \\
\hline $\begin{array}{l}\text { Monthly } \\
\text { expenditure }\end{array}$ & 0.000136 & $(0.0396)$ & $0.0667 * * *$ & $(8.641)$ & $-0.0520 * * *$ & $(-7.120)$ \\
\hline Rural location & $-0.0194 * * *$ & $(-3.623)$ & $-0.0971 * * *$ & $(-7.579)$ & 0.00895 & $(0.791)$ \\
\hline Household size & $0.0296 * * *$ & $(17.06)$ & $0.0754 * * *$ & $(18.84)$ & $0.0436 * * *$ & $(12.04)$ \\
\hline $\begin{array}{l}\text { Mean household } \\
\text { age }\end{array}$ & $-0.000641 * *$ & $(-2.090)$ & $-0.00150 * *$ & $(-2.339)$ & $-5.19 \mathrm{e}-05$ & $(-0.0765)$ \\
\hline $\begin{array}{l}\text { Working } \\
\text { household } \\
\text { members }\end{array}$ & $0.0178 * * *$ & $(6.990)$ & $0.0424 * * *$ & $(7.378)$ & $0.0284 * * *$ & $(5.371)$ \\
\hline $\begin{array}{l}\text { Number of } \\
\text { children }\end{array}$ & -0.000280 & $(-0.105)$ & 0.00134 & $(0.229)$ & 0.00310 & $(0.543)$ \\
\hline Dummy 1997 & $0.0466 * * *$ & $(6.054)$ & $0.109 * * *$ & $(6.907)$ & $0.0519 * * *$ & $(3.541)$ \\
\hline Dummy 2000 & $0.0665 * * *$ & $(8.735)$ & $0.171 * * *$ & $(10.70)$ & $0.0592 * * *$ & $(4.233)$ \\
\hline Dummy 2007 & $0.0698 * * *$ & $(9.469)$ & $0.246^{* * *}$ & (14.41) & $0.0251 *$ & $(1.885)$ \\
\hline Observations & 27,318 & & 15,666 & & 16,173 & \\
\hline Number of groups & 11,242 & & 7,907 & & 8,231 & \\
\hline
\end{tabular}

(2)

(3)

Dual burden-

normal/underweight Dual burden-overweight

Source: IFLS1, IFLS2, IFLS3, IFLS4

Note: Z-statistics in parentheses. $* * *, * *$, and * means significant at the $1 \%$, 5\%, and $10 \%$ level, respectively. Province dummies were included in the analysis but are not shown in the table. Expenditure adjusted by Consumer Price Index. Base category for education of household head is "no education". Base category for household head occupation is "sedentary work". 
Table 13: Panel regressions with Theil index

(1)

(2)

Fixed effects

Random effects

\begin{tabular}{|c|c|c|c|c|}
\hline Primary school & -0.00437 & $(-0.0895)$ & $0.0902 * *$ & $(2.403)$ \\
\hline Secondary school & 0.0112 & $(0.170)$ & $0.141 * * *$ & (3.297) \\
\hline Tertiary education & -0.134 & $(-1.361)$ & $0.172 * * *$ & $(3.082)$ \\
\hline Light work & 0.0296 & $(0.509)$ & -0.0514 & $(-1.240)$ \\
\hline Medium work & -0.0407 & $(-0.675)$ & $-0.119 * * *$ & $(-2.777)$ \\
\hline Heavy work & 0.0117 & $(0.189)$ & $-0.216 * * *$ & $(-4.857)$ \\
\hline Housekeeping & 0.0184 & $(0.245)$ & -0.0866 & $(-1.432)$ \\
\hline Unemployed & -0.0861 & $(-0.974)$ & $-0.166^{* *}$ & $(-2.239)$ \\
\hline Retired & 0.0656 & $(0.880)$ & -0.0958 & $(-1.576)$ \\
\hline Female household head & $-0.292 * * *$ & $(-5.935)$ & $-0.194 * * *$ & $(-5.021)$ \\
\hline Age of household head & $0.0155^{* * *}$ & $(9.219)$ & $0.0216^{* * *}$ & (16.27) \\
\hline Monthly expenditure & 0.0123 & $(0.592)$ & $0.0742 * * *$ & $(4.627)$ \\
\hline Rural location & -0.0836 & $(-1.533)$ & $-0.169 * * *$ & $(-6.774)$ \\
\hline Household size & $0.139 * * *$ & $(13.40)$ & $0.142 * * *$ & $(17.39)$ \\
\hline Mean household age & $-0.0327 * * *$ & $(-18.74)$ & $-0.0290 * * *$ & $(-17.66)$ \\
\hline Working hh members (no.) & 0.00409 & $(0.293)$ & $0.0236 * *$ & $(2.160)$ \\
\hline Number of children & $0.0455^{* * *}$ & $(3.070)$ & $0.0667 * * *$ & $(5.661)$ \\
\hline Dummy 1997 & $0.293 * * *$ & (10.66) & $0.245^{* * *}$ & $(9.529)$ \\
\hline Dummy 2000 & $0.405^{* * *}$ & (14.47) & $0.324 * * *$ & $(12.31)$ \\
\hline Dummy 2007 & $0.651^{* * *}$ & (19.86) & $0.464 * * *$ & $(16.36)$ \\
\hline Constant & $-6.578 * * *$ & $(-19.66)$ & $-7.326 * * *$ & $(-33.95)$ \\
\hline Observations & 27,318 & & 27,318 & \\
\hline R-squared & 0.110 & & 0.125 & \\
\hline Number of households & 11,242 & & 11,242 & \\
\hline
\end{tabular}

Source: IFLS1, IFLS2, IFLS3, IFLS4

Note: $* * * * *$, and $*$ means significant at the $1 \%, 5 \%$, and $10 \%$ level, respectively. Province dummies were included in the analysis but are for space reasons here omitted. Expenditure adjusted by Consumer Price Index. Base category for education of household head is "no education". Base category for occupation of the household head is "sedentary work".

In column 3 of Table 12, the comparison group is overweight households. Here we have less significant effects and for education and expenditures the relationship changes. The probability of being a dual burden household decreases with high income and increased education. Female household heads, rural locations and mean household age are no longer significant. 
The Theil index regressions focus on the intra-household nutritional inequality independent of the categorization of the household (Table 13). Higher education of the household head is associated with higher inequality levels within the household. Thus, higher education of the household is no proxy for possible health knowledge. But health knowledge can be important since children (especially the youngest) are in need of certain micronutrients (Block, 2007; Rivera et al., 2003). If household heads and caregivers do not know about these special needs, they can create health inequalities in the household through purchasing decisions. For example, when food low in micronutrients is provided, this can lead to malnutrition and impact intra-household inequality. Both children and adults need micronutrients, with adults that are overweight often being micronutrientdeficient, showing that calorie input is not a sufficient measure of nutrition (Asfaw, 2007b). Even though health indicators are probably important to be considered (Lee et al., 2010) when trying to include medical measures like water origin or medical expenditures, these did not increase the model fit and were thus left out.

A female household head is significantly and negatively associated with less nutritional inequality in the Theil regressions, independent of weight categories of the household members. Thus, the idea that women often allocate resources to basic needs and to children thus having a positive effect on family health is confirmed in our study (e.g. Rogers, 1996; Thomas, 1990).

Expenditures are only positively correlated with intra-household inequality in the random effects regression (Table 13). Urban location is again associated with a higher intra-household nutritional inequality. In addition, the age of the household head, the household size and the number of children are in all three specifications positively and significantly correlated with the Theil index. Some of the time-invariant variables are not significant in the fixed effect equation e.g., education, some of the occupation variables, expenditures, rural location and the number of working household members. The education 
and occupation variables in the random effects regressions have the same sign as in the probit regressions in the comparison with normal/underweight households.

Generally, we see in the Theil regressions that nutritional inequality will increase further over time since factors such as higher education, higher expenditures, less physical activity, higher age and urban life are positively associated with the Theil index and all these factors are expected to increase further with development and urbanization. This is supported by the time dummies showing an increase in inequality over time.

\subsubsection{LIMITATIONS}

The limitations of our study, and of studies such as this, mainly concern the measurements. A main limitation of the categorization measure is that we are arbitrarily selecting households into categories when there is one overweight member. The number of overweight individuals in the household is not considered. The same is true also for underweight individuals. The number of members with a certain weight status in a category does not count. Therefore, groups are still very heterogeneous within the categories. We tried to cover this limitation by introducing a new measure in this field of research. The Theil index of nutritional inequality showed many similarities to the results found with the categorization but provides a more exact measurement at the household level. Moreover, it gives the opportunity to analyze more in depth the higher inequality levels also for overweight households which share many characteristics with the dual burden households.

Child measurements below the age of five can still be criticized and different measurements have certain drawbacks (de Haen et al., 2011). For example, it is questionable how growth standards with several ethnicities included in the reference group account for different populations since an average of these does not necessarily represent an optimal growth curve of a certain population (de Haen et al., 2011). Until now, 
differences in optimal growth curves between different ethnic groups until the age of 5 is assumed insignificant (de Onis, 2006). Child measurements that are specifically-targeted to particular populations would be an important improvement for research.

\subsection{CONCLUSION}

Our research incorporates for the first time panel data in this type of analysis and applies a newly introduced measure of intra-household inequality. Dual burden households continue to be a concern in Indonesia. Around 20 percent of all households have overweight and underweight members. Children comprise much of the underweight members and female adults the overweight. Even poorer households are increasingly affected by this problem. Even more concerning may be that trends over time show that dual burden households are households in transition that develop to mainly overweight households in the future. Occasionally, households again face the problem of underweight in later periods, documenting the high vulnerability of households in Indonesia.

Since the classification of the households is very rough, we included a new measure for this type of research. The intra-household nutritional Theil index is a continuous measure that better describes nutritional inequality since it is an exact measurement of differences in nutritional outcome at the household level. The Theil index shows significant increases over time in contrast to the share of dual burden households which remains constant from 1997 onwards. With this measure, we found that intra-household inequality is also increasing over time in overweight households. This is in contrast to a simple categorization measure and provides new insights.

The association between intra-household nutritional inequality and household expenditures changes over time and shows similar trends observed for obesity. Rather than being more a problem of the rich only, with time, it becomes more and more of a problem for the poorer strata. In addition, households with high inequality measurements by the 
categorization as well as with the Theil index tend to be more urban, have lower shares of occupations in heavy work, higher consumption in meat and dairy products, with lower consumption of rice, as well as higher rates of television possession. Dual burden households are those changing their behavior in the way generally associated with the nutrition transition.

Inequality is also expected to increase in Indonesia and this is supported by what we see with the time trend in our data. Many factors like urbanization, expenditures and education positively associated with the Theil index in regressions will increase in the future. Female decision-making supports a more equal distribution and/or better adaption to personal needs, lowering inequality. Their focus on children is especially valuable since children's nutritional status is not determined primarily by the food quantity but also food composition and healthcare.

The results of our study document the complex challenge governments in developing countries are facing. Targeting households is very difficult if the nutritional discrepancy is high within a household. Increasing nutritional quality will help to more equalize the distribution of nutritional outcomes at a household level. Policymakers need to be aware of all of the different kinds of nutritional outcomes that exist in the country. Onesided actions that address only underweight by increasing available calories might not be a good way of solving some of the problems this research has documented. Long-term strategies will be needed that can promote the consumption of healthy food with all the critical micronutrients that support development and healthy growth of children. The connection of intra-household inequality and changing lifestyles but also the upcoming obesity epidemic requires adapted policy action to emphasize the healthy ingredients in traditional food.

In terms of policy actions, this may mean that food interventions targeted to children such as school meals, will need to consider the quality of the diet in addition to the 
caloric input. Fortification is one cheap way of reducing many micronutrient deficiencies when there are severe shortages across the population. For adults, especially those of middle-age and females, it is important to raise awareness for the problem of overweight. Furthermore, nutritional quality in general can be improved by increasing the health and nutrition knowledge of mothers or other primary caregivers who are responsible for purchasing and distributing food in the household. Since women often can be shown to have an equalizing effect on the nutritional outcomes within the household, their empowerment in household decisions should be further supported. In addition to addressing these societal burdens from the perspective of nutrition and food, the healthcare and sanitation system is important especially in Indonesia where healthcare quality is poor and individuals have to pay privately for healthcare. An improvement of this system could further reduce the nutritional inequalities currently documented.

In summary, the most important lesson to be taken from this analysis is that policies targeting the problem of underweight need to take into account the current and future problem of overweight. Similarly, strategies targeting overweight should keep in mind that underweight still exists. For this reason, policy interventions need to be well-organized to avoid counter-balancing goals to decrease nutritional inequality within not only the country, but also the household. 


\section{CONCLUSION}

\subsection{SYNOPSIS}

Nutrition and other lifestyle patterns in developing countries are undergoing profound changes, as these countries strive to reduce poverty and increase living standards. Rising incomes, urbanization, globalization and technology innovation are the main factors contributing to this change. The nutrition transition brings with it changes in food consumption, with meat and dairy products increasingly included in the daily diet. Individuals are eating more sugar and fat that is often hidden in processed foods from the supermarket and food eaten away from home. Overweight and obesity are increasingly a problem and presenting an additional challenge to the still prevalent underweight problem. Countries are facing both communicable diseases and non-communicable diseases as consequences from malnutrition. These are responsible for high losses through increased health costs and decreased productivity.

These developments have been apparent for some time in Latin America, North Africa and the Middle East. Recently, parts of Africa and Asia are becoming affected by these changes as well. In Asia (especially China but also Thailand and Malaysia) the rapid spread of these developments can be witnessed. Even though "hunger" was a much greater 
problem in Indonesia in the past, recent evidence suggests that the nutritional transition is taking place. Incomes are rising, urbanization is increasing and supermarkets and television are becoming more common.

In this study we investigated nutritional development over time in Indonesia. We find that obesity and overweight in Asia should be measured with ethnicity-specific measurements so that the risk of morbidity and mortality is correctly assessed. A large part of the population was found to already be overweight and obese. All expenditure quintiles and even the rural area are affected, but women especially. The physical activity of the occupation, expenditures, and proxies for household chores and television are positively associated with the BMI. Rural locations are negatively associated with the BMI even when controlling for all other influences.

In order to analyze nutritional inequality at the household level, we used two measures. The household categorization was accompanied by a new measure in this field of research: the intra-household Theil index of nutrition. Dual burden households compromise a significant share of households in Indonesia. Children are mostly those underweight, while adults (especially women in middle age) are those overweight. Even though the share of dual burden households stays stable over time, the households fluctuate from this category into others, in particular overweight households. The transitional notion is further compounded since characteristics of the nutrition transition such as higher meat and dairy consumption relative to grains and the possession of a television can be found in dual burden households. These seem to be the households that are within the nutrition transition process.

The Theil index gives further insight because it more precisely measures intrahousehold inequality and can thus also measure intra-household inequality across the categories calculated before. Here we see that apart from the dual burden category, intrahousehold inequality is also high in overweight households. Further, we find many 
indications that inequality will increase in the near future. The Theil index in contrast to the dual burden categorization shows a gradual increase over time, especially as all covariates positively associated with the Theil index (income, urbanization and education) are expected to increase over time.

Summarizing our findings, due to the nutrition transition, some nutrition problems are vanishing but others are newly emerging. We generally observe a reduction in undernutrition but an increase in overweight. We find that access and availability of food are not the only nutritional concern anymore. Our second study in particular, showed that undernutrition and overnutrition exist at the same time and even in the same households. The food is available but the intra-household food allocation misses the needs of children too often. These findings point to the fact that with increasing incomes and higher food availability malnutrition is still a big issue. Incentives to change food consumption and to have a more comfortable life are high. Therefore, it will be important to include nutritional and healthy lifestyle information along with efforts to guarantee the individual's access to food. The provisions of nutritional education, healthcare facilities, sanitation systems or disease prevention seem crucial.

\subsection{POLICY IMPLICATIONS}

Overall our study shows that there are nutritional changes in developing countries that challenge policymakers in many different ways. Overweight and obesity are becoming a serious issue for countries undergoing the nutrition transition. These changes occur across all population groups even rural and lower income strata are affected.

Furthermore, while general intra-household inequality of nutrition is increasing and supposed to further increase, our study shows that there is an even greater policy challenge with intra-household inequality. Overweight and underweight members are often found in the same household. Many factors increase the inequality like expenditures, education and 
occupation while female household heads can have a negative impact on this inequality. This shows that the rules of distribution and purchase are heavily influenced by the household head.

Nutrition in developing countries has become a more complex policy challenge over the last years. While further economic growth and poverty reduction are important pathways to reduce malnutrition, special nutrition policies are needed to really fight against it sustainably. Knowledge on nutrition does not trickle down and income does not lead automatically to a well-nourished population. Calorie intake may increase but this will not address all malnutrition issues.

The obesity epidemic has arrived in Indonesia. As can be seen in developed countries, efforts to address this are especially difficult and in developing countries with less financial resources it will be harder. The obesity problem needs to be tackled by increasing awareness in the population for such a problem and challenging the social norms that higher weight is equal to higher social status. This could be addressed in general by campaigns that increase health and nutritional knowledge, emphasizing the use of products like vegetables and fruits. Also the general promotion of indigenous food as opposed to modern and processed supermarket food is important.

With respect to intra-household inequality of nutrition, policies urgently need to consider underweight, overweight, and nutrition simultaneously. Counter-effective strategies should be avoided as only increasing caloric input will not address all of the issues. First, families and individuals need to be aware that overweight is not good for health. In addition, families need to know that mild (non-visible) malnutrition is also influencing mortality, morbidity and cognitive abilities and that especially for children micronutrients are important for their healthy development. Often, these micronutrient deficiencies are not easily detected and nutrition services can assist in diagnosis. Focus on very young children is very important since they often have future impairments that are 
irreversible. For this, mothers need to be the focus since their nutritional status in pregnancy, but also in early child years, heavily influence the child's weight. Women need to be empowered since our study shows that they focus more on basic needs and their children when expenditure and food is provided through their hands.

In Indonesia the government needs to increase expenditures for nutrition and health policies. Many policies are inefficient and an expansion of the healthcare system and increasing its quality is necessary. The capacity of the government to cooperate but also regulate the private sector is important since the food-supplying sector has a major role in offering healthful (e.g. fortified food) but also counter-productive food (e.g. with high fat and sugar content or fast food).

In the end all the investments in health or nutrition will pay out since the population will be more productive because of higher cognitive abilities, less sickness and a higher quality of life. The returns to invest in nutrition are relatively high in comparison with other policy actions.

\subsection{FURTHER RESEARCH}

Research in this area is confronted with several problems. First, anthropometrics and especially classifications of nutritional status are problematic. In general, there are valid concerns about population-specific optimal growth curves for children and optimal weight ranges for adults. For adults there is the option of using different cut-off values discovered through research but no strict policy exists to guide their use for particular countries. Even between Asian countries there are huge differences in optimal weight ranges. We believe that the international cut-offs should not be used in the Indonesian case since comparability with the Caucasian population is not given. For children, it becomes even more difficult. Further studies on optimal growth studies for specific populations are a future task that would increase the reliability of research results. 
A second challenge in this research is that especially in large-scale country surveys information on food consumption is often not reliable. In our case, we had to use expenditure data to proxy nutritional input. Further, this data is collected at the household level where we cannot draw exact conclusions about each individual's input. Therefore, intra-household distribution is completely neglected which especially for Chapter 3 would be of importance and bring further insights. Nevertheless, we know that it is expensive and burdensome to incorporate such detailed information on nutritional input in large household surveys. Thus, the combination of this study with a small-scale survey in Indonesia, in which the information could be asked more exactly, would bring additional insights on obesity and intra-household inequality determinants.

Additionally, especially for the second study, decision-making data is clearly desirable. Even though the IFLS data of 2007 offered a small section on decision making information, quality and scope of the data were very limited and could not be used effectively. Thus, with additional surveys that add information, more insights could be gained. This is important since good and balanced nutrition is one cornerstone for development as it promotes health, productivity and higher ability. Large-scale efforts by governments and others should be made to improve the nutritional status by fighting overweight and underweight at the same time. We believe that the yield of the efforts will be worth the expense. 


\section{REFERENCES}

Alderman, H., P.A. Chiappori, L. Haddad, J. Hoddinott, and R. Kanbur. (1995). Unitary versus collective models of the household: is it time to shift the burden of proof? World Bank Research Observer, 10 (1), 1-19.

Allen, L.H. (2003). Interventions for micronutrient deficiency control in developing countries: past, present and future. Journal of Nutrition, 133 (11), 3875S-3878S.

Araar, A., S. Levine, and J.-Y. Duclos. (2009). Body Mass Index, Poverty and Inequality in Namibia. Paper Prepared for the Central Bureau of Statistics.

Asfaw, A. (2007a). Do government food price policies affect the prevalence of obesity? Empirical evidence from Egypt. World Development, 35 (4), 687-701.

. (2007b). Micronutrient deficiency and the prevalence of mothers' overweight/obesity in Egypt. Economics \& Human Biology, 5 (3), 471-483.

(2008). Does supermarket purchase affect the dietary practices of households? Some empirical evidence from Guatemala. Development Policy Review, 26 (2), 227-243.

Balarajan, Y., and E. Villamor. (2009). Nationally Representative Surveys Show Recent Increases in the Prevalence of Overweight and Obesity among Women of Reproductive Age in Bangladesh, Nepal, and India. Journal of Nutrition, 139 (11), 2139-2144.

Baltagi, B.H. (2005). Econometric Analysis of Panel Data. West Sussex: John Wiley \& Sons.

Black, R.E., L.H. Allen, Z.A. Bhutta, L.E. Caulfield, M. de Onis, M. Ezzati, C. Mathers, and J. Rivera. (2008). Maternal and child undernutrition: global and regional exposures and health consequences. Lancet, 371 (9608), 243-260.

Block, S.A. (2007). Maternal nutrition knowledge versus schooling as determinants of child micronutrient status. Oxford Economic Papers, 59 (2), 330-353. 
BPS, BAPPENAS, and UNDP. (2004). The Economics of Democracy Financing human development in Indonesia. National Human Development Report 2004.

Case, A., and A. Menendez. (2009). Sex differences in obesity rates in poor countries: evidence from South Africa. Economics \& Human Biology, 7 (3), 271-282.

CCC. (2004). Copenhagen Consensus 2004: The Results. Copenhagen Consensus Center, Copenhagen.

Chan, J.C., and J. Sobal. (2011). Family meals and body weight. Analysis of multiple family members in family units. Appetite, 57 (2), 517-524.

Chiolero, A., D. Faeh, F. Paccaud, and J. Cornuz. (2008). Consequences of smoking for body weight, body fat distribution, and insulin resistance. American Journal of Clinical Nutrition, 87 (4), 801-809.

Cole, T.J., K.M. Flegal, D. Nicholls, and A.A. Jackson. (2007). Body mass index cut offs to define thinness in children and adolescents: international survey. BMJ, 335 (7612), 194.

Collins, A.E., B. Pakiz, and C.L. Rock. (2008). Factors associated with obesity in Indonesian adolescents. International Journal of Pediatric Obesity, 3 (1), 58-64.

de Haen, H., S. Klasen, and M. Qaim. (2011). What do we really know? Metrics for food insecurity and undernutrition. Food Policy, 36 (6), 760-769.

de Onis, M. (2006). Assessment of differences in linear growth among populations in the WHO Multicentre Growth Reference Study. Acta Paediatrica, 95, 56-65.

(2010). Defining obesity risk status in the general childhood population: Which cut-offs should we use? International Journal of Pediatric Obesity, 5 (6), 458-461.

de Onis, M., M. Blössner, and E. Borghi. (2010). Global prevalence and trends of overweight and obesity among preschool children. American Journal of Clinical Nutrition, 92 (5), 12571264 .

de Onis, M., M. Blössner, E. Borghi, E.A. Frongillo, and R. Morris. (2004). Estimates of global prevalence of childhood underweight in 1990 and 2015. Journal of the American Medical Association, 291 (21), 2600-2606.

de Onis, M., A. Onyango, E. Borghi, A. Siyam, C. Nishida, and J. Siekmann. (2007). Development of a WHO growth reference for school-aged children and adolescents. Bulletin of the World Health Organization, 85 (9), 660-667.

Dearth-Wesley, T., H. Wang, and B.M. Popkin. (2008). Under- and overnutrition dynamics in Chinese children and adults (1991-2004). European Journal of Clinical Nutrition, 62 (11), 1302-1307.

Delgado, C.L. (2003). Rising consumption of meat and milk in developing countries has created a new food revolution. Journal of Nutrition, 133 (11), 3907s-3910s. 
Deurenberg, P., M. Deurenberg-Yap, and S. Guricci. (2002). Asians are different from Caucasians and from each other in their body mass index/body fat per cent relationship. Obesity Reviews, 3 (3), 141-146.

Doak, C.M., L. Adair, M. Bentley, F.Y. Zhai, and B.M. Popkin. (2002). The underweight/ overweight household: an exploration of household sociodemographic and dietary factors in China. Public Health Nutrition, 5 (1A), 215-221.

Doak, C.M., L.S. Adair, M. Bentley, C. Monteiro, and B.M. Popkin. (2005). The dual burden household and the nutrition transition paradox. International Journal of Obesity, 29 (1), $129-136$

Doak, C.M., L.S. Adair, C. Monteiro, and B.M. Popkin. (2000). Overweight and underweight coexist within households in Brazil, China and Russia. Journal of Nutrition, 130 (12), 2965-2971.

Doak, C.M., C. Monteiro, and B.M. Popkin. (1999). The coexistence of obesity and undernutrition in the same household is an emerging phenomena in lower income countries. Faseb Journal, 13 (5), A894-A894.

Drèze, J., and A. Sen. (1989). Hunger and public action. Oxford: Oxford University Press.

Du, S.F., B. Lu, F.Y. Zhai, and B.M. Popkin. (2002). A new stage of the nutrition transition in China. Public Health Nutrition, 5 (1A), 169-174.

FAO. (2011). Women in Agriculture: closing the gender gap for development. The State of Food and Agriculture. Food and Agriculture Organization, Rome, Italy.

(2012). World food and agriculture. FAO Statistical Yearbook. FAO, Rome, Italy.

Fernald, L.C. (2007). Socio-economic status and body mass index in low-income Mexican adults. Social Science \& Medicine, 64 (10), 2030-2042.

Fernald, L.C., and L.M. Neufeld. (2006). Overweight with concurrent stunting in very young children from rural Mexico: prevalence and associated factors. European Journal of Clinical Nutrition, 61 (5), 623-632.

Frankenberg, E., and L. Karoly. (1995). The 1993 Indonesian Family Life Survey: overview and field report. RAND, Santa Monica, CA.

Frankenberg, E., and D. Thomas. (2000). The Indonesia Family Life Survey (IFLS): study design and results from waves 1 and 2. DRU-2238/1-NIA/NICHD. RAND, Santa Monica, CA.

Gaiha, R., R. Jha, and V.S. Kulkarni. (2010). Obesity, affluence and urbanisation in India. ASARC Working Papers. 2010/10. Australia South Asia Research Centre,

Galal, O. (2003). Nutrition-related health patterns in the Middle East. Asia Pacific Journal of Clinical Nutrition, 12 (3), 337-343. 
García, O.P., K.Z. Long, and J.L. Rosado. (2009). Impact of micronutrient deficiencies on obesity. Nutrition Reviews, 67 (10), 559-572.

Garrett, J.L., and M.T. Ruel. (2005). Stunted childoverweight mother pairs: prevalence and association with economic development and urbanization. Food \& Nutrition Bulletin, 26, 209-221.

Gerbens-Leenes, P.W., S. Nonhebel, and M.S. Krol. (2010). Food consumption patterns and economic growth. Increasing affluence and the use of natural resources. Appetite, 55 (3), 597-608.

Glewwe, P., and E.A. Miguel. (2007). The impact of child health and nutrition on education in less developed countries. In: Handbook of development economics, ed. T. P. Schultz and A. S. John. Amsterdam, Netherlands: Elsevier.

Guo, S.S., W. Wu, W.C. Chumlea, and A.F. Roche. (2002). Predicting overweight and obesity in adulthood from body mass index values in childhood and adolescence. American Journal of Clinical Nutrition, 76 (3), 653-658.

Gurrici, S., Y. Hartriyanti, J.G. Hautvast, and P. Deurenberg. (1998). Relationship between body fat and body mass index: differences between Indonesians and Dutch Caucasians. European Journal of Clinical Nutrition, 52 (11), 779-783.

Hansford, F. (2010). The nutrition transition: a gender perspective with reference to Brazil. Gender and Development, 18 (3), 439-452.

Hawkes, C. (2008). Dietary implications of supermarket development: a global perspective. Development Policy Review, 26 (6), 657-692.

Hoddinott, J., and L. Haddad. (1995). Does female income share influence household expenditures? Evidence from Côte d'Ivoire. Oxford Bulletin of Economics and Statistics, 57 (1), 77-96.

Hoffman, D.J., A.L. Sawaya, I. Verreschi, K.L. Tucker, and S.B. Roberts. (2000). Why are nutritionally stunted children at increased risk of obesity? Studies of metabolic rate and fat oxidation in shantytown children from Sao Paulo, Brazil. American Journal of Clinical Nutrition, 72 (3), 702.

Huffman, S.K., and M. Rizov. (2010). The rise of obesity in transition: theory and empirical evidence from Russia. Journal of Development Studies, 46 (3), 574-594.

James, P.T., R. Leach, E. Kalamara, and M. Shayeghi. (2001). The worldwide obesity epidemic Obesity, 9, 228S-233S.

Jehn, M., and A. Brewis. (2009). Paradoxical malnutrition in mother-child pairs: untangling the phenomenon of over- and under-nutrition in underdeveloped economies. Economics \& Human Biology, 7 (1), 28-35. 
Jones-Smith, J.C., P. Gordon-Larsen, A. Siddiqi, and B.M. Popkin. (2011a). Emerging disparities in overweight by educational attainment in Chinese adults (1989-2006). International Journal of Obesity, doi:10.1038/ijo.2011.179.

. (2011b). Is the burden of overweight shifting to the poor across the globe? Time trends among women in 39 low- and middle-income countries (1991-2008). International Journal of Obesity, doi:10.1038/ijo.2011.179.

Kelishadi, R. (2007). Childhood overweight, obesity, and the metabolic syndrome in developing countries. Epidemiologic Reviews, 29, 62-76.

Kelly, T., W. Yang, C.S. Chen, K. Reynolds, and J. He. (2008). Global burden of obesity in 2005 and projections to 2030. International Journal of Obesity, 32 (9), 1431-1437.

Khor, G.L. (2008). Food-based approaches to combat the double burden among the poor: challenges in the Asian context. Asia Pacific Journal of Clinical Nutrition, 17, 111-115.

Khor, G.L., and Z.M. Sharif. (2003). Dual forms of malnutrition in the same households in Malaysia - a case study among Malay rural households. Asia Pacific Journal of Clinical Nutrition, 12 (4), 427-437.

Kimani-Murage, E., K. Kahn, J. Pettifor, S. Tollman, D. Dunger, X. Gomez-Olive, and S. Norris. (2010). The prevalence of stunting, overweight and obesity, and metabolic disease risk in rural South African children. Bmc Public Health, 10 (1), 158.

Kosulwat, V. (2002). The nutrition and health transition in Thailand. Public Health Nutrition, 5 (1A), 183-189.

Kurniawan, A. (2002). Policies in alleviating micronutrient deficiencies: Indonesia's experience. Asia Pacific Journal of Clinical Nutrition, 11, S360-S370.

Lakdawalla, D., and T. Philipson. (2009). The growth of obesity and technological change. Economics \& Human Biology, 7 (3), 283-293.

Lee, C.M.Y., A.L.C. Martiniuk, M. Woodward, V. Feigin, D.F. Gu, K. Jamrozik, T.H. Lam, C.N. Mhurchu, W.H. Pan, I. Suh, H. Ueshema, J. Woo, and R. Huxley. (2007). The burden of overweight and obesity in the Asia-Pacific region. Obesity Reviews, 8 (3), 191-196.

Lee, J., R.F. Houser, A. Must, P.P. de Fulladolsa, and O.I. Bermudez. (2010). Disentangling nutritional factors and household characteristics related to child stunting and maternal overweight in Guatemala. Economics \& Human Biology, 8 (2), 188-196.

Lee, J., R.F. Houser, A. Must, P. Palma de Fulladolsa, and O.I. Bermudez. (2011). Socioeconomic disparities and the familial coexistence of child stunting and maternal overweight in Guatemala. Economics \& Human Biology, 10 (3), 232-241.

Lipoeto, N.I., N. Wattanapenpaiboon, A. Malik, and M.L. Wahlqvist. (2004). The nutrition transition in West Sumatra, Indonesia. Asian Pacific Journal of Clinical Nutrition, 13 (3), 312-316. 
Lobato, J.C.P., A.J.L. Costa, and R. Sichieri. (2009). Food intake and prevalence of obesity in Brazil: an ecological analysis. Public Health Nutrition, 12 (11), 2209-2215.

Lu, Y., and D. Goldman. (2010). The effects of relative food prices on obesity: evidence from China: 1991-2006. NBER Working Papers No. 15720. 15720. Cambridge, MA: National Bureau of Economic Research.

Ma, B. (2010). Socioeconomic status and overweight and obesity: how does the gradient change with age? New evidence from China. UMBC Economics Department Working Papers. No 10-122. Baltimore: UMBC Department of Economics.

Martorell, R., L.K. Khan, M.L. Hughes, and L.M. Grummer-Strawn. (2000). Obesity in women from developing countries. European Journal of Clinical Nutrition, 54 (3), 247-252.

Mehio Sibai, A., L. Nasreddine, A.H. Mokdad, N. Adra, M. Tabet, and N. Hwalla. (2010). Nutrition transition and cardiovascular disease risk factors in Middle East and North Africa countries: reviewing the evidence. Annals of Nutrition and Metabolism, 57 (3-4), 193-203.

Mei, Z., L.M. Grummer-Strawn, A. Pietrobelli, A. Goulding, M.I. Goran, and W.H. Dietz. (2002). Validity of body mass index compared with other body-composition screening indexes for the assessment of body fatness in children and adolescents. American Journal of Clinical Nutrition, 75 (6), 978-985.

Mendez, M.A., C.A. Monteiro, and B.M. Popkin. (2005). Overweight exceeds underweight among women in most developing countries. American Journal of Clinical Nutrition, 81 (3), 714721.

Mokhtar, N., J. Elati, R. Chabir, A. Bour, K. Elkari, N.P. Schlossman, B. Caballero, and H. Aguenaou. (2001). Diet culture and obesity in Northern Africa. Journal of Nutrition, 131 (3), $887 \mathrm{~s}-892 \mathrm{~s}$.

Molini, V., M. Nube, and B. van den Boom. (2010). Adult BMI as a health and nutritional inequality measure: applications at macro and micro levels. World Development, 38 (7), 1012-1023.

Monda, K.L., P. Gordon-Larsen, J. Stevens, and B.M. Popkin. (2007). China's transition: the effect of rapid urbanization on adult occupational physical activity. Social Science \& Medicine, 64 (4), 858-870.

Ng, S.W., E.C. Norton, D.K. Guilkey, and B.M. Popkin. (2010). Estimation of a dynamic model of weight. NBER Working Papers. Cambridge, MA: National Bureau of Economic Research.

Ng, S.W., E.C. Norton, and B.M. Popkin. (2009). Why have physical activity levels declined among Chinese adults? Findings from the 1991-2006 China health and nutrition surveys. Social Science \& Medicine, 68 (7), 1305-1314.

Norman, A., T. Moradi, G. Gridley, M. Dosemeci, B. Rydh, O. Nyren, and A. Wolk. (2002). Occupational physical activity and risk for prostate cancer in a nationwide cohort study in Sweden. British Journal of Cancer, 86 (1), 70-75. 
OECD. (2010). OECD Economic Review of Indonesia. OECD Economic Reviews. OECD, Paris.

Offer, A., R. Pechey, and S. Ulijaszek. (2010). Obesity under affluence varies by welfare regimes: the effect of fast food, insecurity, and inequality. Economics \& Human Biology, 8 (3), 297308.

Olson, C.M., C.F. Bove, and E.O. Miller. (2007). Growing up poor: long-term implications for eating patterns and body weight. Appetite, 49 (1), 198-207.

Penman, A.D., and W.D. Johnson. (2006). The changing shape of the body mass index distribution curve in the population: implications for public health policy to reduce the prevalence of adult obesity. Preventing Chronic Disease, 3 (3), 1-4.

Pinstrup-Andersen, P. (2007). Agricultural research and policy for better health and nutrition in developing countries: a food systems approach. Agricultural Economics, 37 (s1), 187-198.

Popkin, B.M. (2003). The nutrition transition in the developing world. Development Policy Review, $21(5-6), 581-597$.

. (2010). Recent dynamics suggest selected countries catching up to US obesity. American Journal of Clinical Nutrition, 91 (1), 284s-288s.

Popkin, B.M., L.S. Adair, and S.W. Ng. (2012). Global nutrition transition and the pandemic of obesity in developing countries. Nutrition Reviews, 70 (1), 3-21.

Popkin, B.M., and C.M. Doak. (1998). The obesity epidemic is a worldwide phenomenon. Nutrition Reviews, 56 (4), 106-114.

Popkin, B.M., and P. Gordon-Larsen. (2004). The nutrition transition: worldwide obesity dynamics and their determinants. International Journal of Obesity, 28, S2-S9.

Popkin, B.M., S. Horton, S. Kim, A. Mahal, and S.G. Jin. (2001). Trends in diet, nutritional status, and diet-related noncommunicable diseases in China and India: The economic costs of the nutrition transition. Nutrition Reviews, 59 (12), 379-390.

Popkin, B.M., M.K. Richards, and C.A. Monteiro. (1996). Stunting is associated with overweight in children of four nations that are undergoing the nutrition transition. Journal of Nutrition, 126 (12), 3009-3016.

Prentice, A.M. (2006). The emerging epidemic of obesity in developing countries. International Journal of Epidemiology, 35 (1), 93-99.

Reardon, T., C.P. Timmer, C.B. Barrett, and J. Berdegue. (2003). The rise of supermarkets in Africa, Asia, and Latin America. American Journal of Agricultural Economics, 85 (5), $1140-1146$.

Rivera, J.A., S. Barquera, T. González-Cossío, G. Olaiz, and J. Sepúlveda. (2004). Nutrition transition in Mexico and in other Latin American countries. Nutrition Reviews, 62, S149S157. 
Rivera, J.A., C. Hotz, T. González-Cossío, L. Neufeld, and A. García-Guerra. (2003). The effect of micronutrient deficiencies on child growth: a review of results from community-based supplementation trials. Journal of Nutrition, 133 (11), 4010S-4020S.

Roemling, C., and M. Qaim. (2012). Obesity trends and determinants in Indonesia. Appetite, 58 (3), 1005-1013.

Rogers, B.L. (1996). The implications of female household headship for food consumption and nutritional status in the Dominican Republic. World Development, 24 (1), 113-128.

Rokx, C., G. Schieber, P. Harimurti, A. Tandon, and A. Somanathan. (2009). Health financing in Indonesia: a reform road-map. Directions in Development. World Bank, Washington D.C.

Sahn, D.E., and S.D. Younger. (2009). Measuring intra-household health inequality: explorations using the Body Mass Index. Health Economics, 18 (1), S13-S36.

Saibul, N., Z.M. Shariff, K.G. Lin, M. Kandiah, N.A. Ghani, and H.A. Rahman. (2009). Food variety score is associated with dual burden of malnutrition in Orang Asli (Malaysian indigenous peoples) households: implications for health promotion. Asia Pacific Journal of Clinical Nutrition, 18 (3), 412-422.

Sen, A.K. (1981). Poverty and famines: an essay on entitlement and deprivation. Oxford: Clarendon Press.

Strauss, J., K. Beegle, B. Sikoki, A. Dwiyanto, Y. Herawati, and F. Witoelar. (2004). The third wave of the Indonesia Family Life Survey (IFLS): overview and field report. WR-144/1NIA/NICHD.

Strauss, J., F. Witoelar, B. Sikoki, and A.M. Wattie. (2009). The fourth wave of the Indonesian Family Life Survey (IFLS4): overview and field report. WR-675/1-NIA/NICHD.

Subramanian, S.V., J.M. Perkins, E. Oezaltin, and G. Davey-Smith. (2011). Weight of nations: a socioeconomic analysis of women in low- to middle-income countries. American Journal of Clinical Nutrition, 93 (2), 413-421.

Suryahadi, A., S. Sumarto, and L. Pritchett. (2003). Evolution of poverty during the crisis in Indonesia. Asian Economic Journal, 17 (3), 221-241.

Thomas, D. (1990). Intra-household resource allocation: An inferential approach. Journal of Human Resources, 25, 635-664.

Thomas, D., and E. Frankenberg. (2007). Household responses to the financial crisis in Indonesia: Longitudinal evidence on poverty, resources, and well-being. In: Globalization and Poverty, ed. A. Harrison. Chicago: University of Chicago Press.

Uauy, R., C. Albala, and J. Kain. (2001). Obesity trends in Latin America: Transiting from underto overweight. Journal of Nutrition, 131 (3), 893s-899s.

UN. (2006). UN millennium project. New York, United States: UNDP. www.unmillenniumproject.org. (accessed 03/21/2012). 
UNICEF. (2012a). At-a-glance: China statistics. New York: UNICEF. http://www.unicef.org/infobycountry/china_statistics.html (accessed 03/06/2012).

(2012b). At-a-glance: India statistics. New York: UNICEF.

http://www.unicef.org/infobycountry/india statistics.html. (accessed 03/06/2012).

(2012c). At-a-glance: Indonesia statistics. New York: UNICEF.

http://www.unicef.org/infobycountry/indonesia_statistics.html. (accessed 6. March 2012).

Usfar, A.A., and U. Fahmida. (2011). Do Indonesians follow its dietary guidelines? Evidence related to food consumption, healthy lifestyle, and nutritional status within the period 2000-2010. Asia Pacific Journal of Clinical Nutrition, 20 (3), 484-494.

Usfar, A.A., E. Lebenthal, Atmarita, E. Achadi, Soekirman, and H. Hadi. (2010). Obesity as a poverty-related emerging nutrition problems: the case of Indonesia. Obesity Reviews, 11 (12), 924-928.

Victora, C.G., L. Adair, C. Fall, P.C. Hallal, R. Martorell, L. Richter, and H.S. Sachdev. (2008). Maternal and child undernutrition: consequences for adult health and human capital. Lancet, 371 (9609), 340-357.

Vio, F., C. Albala, and J. Kain. (2008). Nutrition transition in Chile revisited: mid-term evaluation of obesity goals for the period 2000-2010. Public Health Nutrition, 11 (4), 405-412.

Waters, H., F. Saadah, and M. Pradhan. (2003). The impact of the 1997-98 East Asian economic crisis on health and health care in Indonesia. Health Policy and Planning, 18 (2), 172-181.

WHO. (1995). Physical status: the use and interpretation of anthropometry. WHO Technical Report Series No. 854. Geneva: WHO.

. (2000). Obesity: preventing and managing the global epidemic. WHO Technical Report Series No. 894. Geneva: WHO.

. (2004). Appropriate body-mass index for Asian populations and its implications for policy and intervention strategies. Lancet, 363, 157-163.

. (2009). WHO child growth standards: growth velocity based on weight, length and head circumference : methods and development. WHO, Geneva.

(2011). World health statistics 2011. WHO, Geneva.

. (2012). Growth reference 5-19 years: BMI-for-age (5-19 years) Geneva: WHO. http://www.who.int/growthref/who2007_bmi_for_age/en/index.html. (accessed 03/27/2012).

Williams, L., J. Germov, and A. Young. (2011). The effect of social class on mid-age women's weight control practices and weight gain. Appetite, 56 (3), 719-725.

World Bank. (2006). Repositioning nutrition as central to development: a strategy for large-scale action. World Bank, Washington. 
. (2007). Horticultural producers and supermarket development in Indonesia. Report No.38543-ID. Report No.38543-ID. Washington D.C: The World Bank.

. (2010). World development indicators 2010. World Bank, Washington.

. (2012). Poverty \& equity data. Washington: World Bank.

http://povertydata.worldbank.org/poverty/home (accessed 03/20/2012).

Ziraba, A., J. Fotso, and R. Ochako. (2009). Overweight and obesity in urban Africa: A problem of the rich or the poor? Bmc Public Health, 9 (1), doi:10.1186/1471-2458-1189-1465. 
6 APPENDIX 
Appendix 1: Descriptive statistics of sample used for panel regressions (2000 and 2007)

\begin{tabular}{|c|c|c|c|c|}
\hline \multirow[b]{2}{*}{ Variable } & \multicolumn{2}{|c|}{ Male $(n=18138)$} & \multicolumn{2}{|c|}{ Female $(n=19378)$} \\
\hline & Mean & Std. Dev. & Mean & Std. Dev. \\
\hline Body mass index (BMI) & 21.66 & 3.38 & 22.99 & 4.25 \\
\hline $\begin{array}{l}\text { Expenditures p.c. }(100 \text { thsd. } \\
\text { rupiah) }\end{array}$ & 4.10 & 4.41 & 4.05 & 4.42 \\
\hline Education $(0-3)$ & 1.60 & 0.73 & 1.39 & 0.80 \\
\hline Rural location (dummy) & 0.51 & 0.50 & 0.50 & 0.50 \\
\hline Married (dummy) & 0.81 & 0.39 & 0.77 & 0.42 \\
\hline Age (years) & 38.76 & 13.05 & 39.23 & 13.42 \\
\hline Smoking (dummy) & 0.71 & 0.46 & 0.03 & 0.16 \\
\hline \multicolumn{5}{|l|}{ Food consumption } \\
\hline Food exp p.c. (100 thsd. rupiah) & 2.17 & 2.11 & 2.10 & 2.03 \\
\hline Meat and dairy share & 0.15 & 0.11 & 0.16 & 0.11 \\
\hline Staple food share & 0.21 & 0.15 & 0.22 & 0.15 \\
\hline \multicolumn{5}{|l|}{ Work-related physical activity } \\
\hline Sedentary work (dummy) & 0.05 & 0.22 & 0.02 & 0.15 \\
\hline Light work (dummy) & 0.28 & 0.45 & 0.27 & 0.44 \\
\hline Medium work (dummy) & 0.26 & 0.44 & 0.07 & 0.25 \\
\hline Heavy work (dummy) & 0.33 & 0.47 & 0.15 & 0.36 \\
\hline Housekeeping (dummy) & 0.02 & 0.15 & 0.47 & 0.50 \\
\hline Unemployed (dummy) & 0.06 & 0.23 & 0.02 & 0.12 \\
\hline \multicolumn{5}{|l|}{ Leisure-related physical activity } \\
\hline $\begin{array}{l}\text { Possession of television (dummy) } \\
\text { Household appliances (100 thsd. } \\
\text { rupiah) }\end{array}$ & 19.78 & 63.45 & 20.14 & 61.42 \\
\hline
\end{tabular}

Source: IFLS3, IFLS4

Note: Monetary values are adjusted using the consumer price index and expressed in thousand rupiah. Food consumption shares are the share of expenditure for a certain product in total food expenditure of a household. For the education variable, 0 stands for no education, 1 for primary education, 2 for secondary education, and 3 for tertiary education. 
Appendix 2: BMI distribution by expenditure quintile (1993 and 2007)
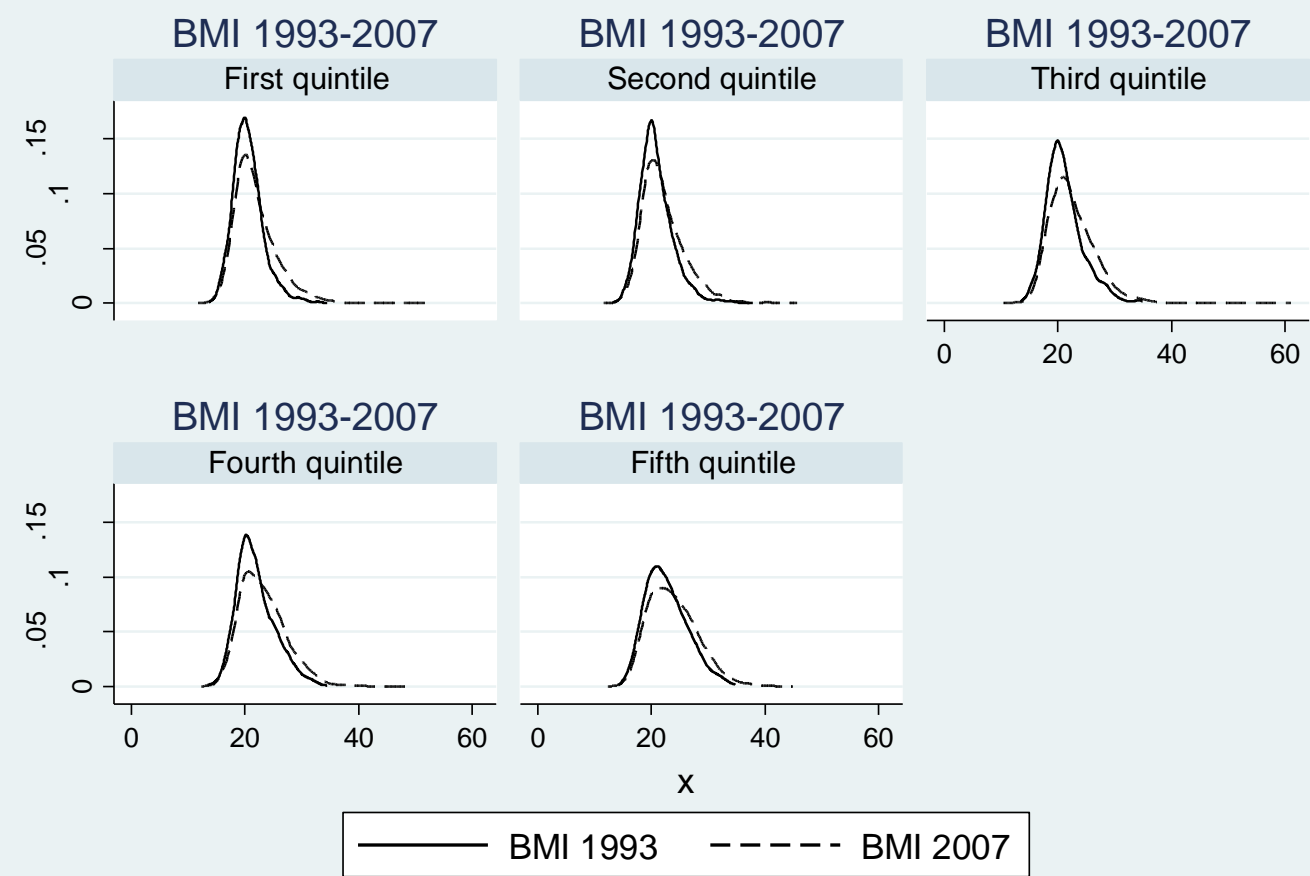

Graphs by five quintiles of household expenditure

Source: IFLS 1, IFLS 4 
Appendix 3: Pooled summary statistics

mean std $\quad$ Min $\quad$ Max

$(\mathrm{n}=27318)$

\begin{tabular}{lcccc}
\hline $\begin{array}{l}\text { Education of household head } \\
\quad \text { No education }\end{array}$ & 0.117 & 0.322 & 0 & 1 \\
$\quad$ Primary school & 0.490 & 0.500 & 0 & 1 \\
$\quad$ Secondary school & 0.323 & 0.468 & 0 & 1 \\
$\quad$ Tertiary education & 0.070 & 0.255 & 0 & 1 \\
$\begin{array}{l}\text { Occupation of household head } \\
\quad \text { Sedentary work }\end{array}$ & 0.048 & 0.214 & 0 & \\
$\quad$ Light work & 0.254 & 0.435 & 0 & 1 \\
$\quad$ Medium work & 0.219 & 0.414 & 0 & 1 \\
$\quad$ Heavy work & 0.343 & 0.475 & 0 & 1 \\
$\quad$ Housekeeping & 0.062 & 0.242 & 0 & 1 \\
$\quad$ Unemployed & 0.022 & 0.147 & 0 & 1 \\
$\quad$ Retired & 0.051 & 0.221 & 0 & 1 \\
Female household head & 0.127 & 0.333 & 0 & 1 \\
Age of household head & Log(household monthly & 13.86 & 17 & 102 \\
expenditure) & 45.39 & 0.751 & 9.41 & 16.69 \\
Rural location & 12.534 & 0.499 & 0 & 1 \\
Household size & 0.533 & 1.822 & 2 & 16 \\
Mean age of household & 4.427 & 13.03 & 9.2 & 99 \\
Working hh members & 30.51 & 0.919 & 0 & 8 \\
Number of children & 1.575 & 1.191 & 0 & 8 \\
\hline
\end{tabular}

Source: IFLS1, IFLS2, IFLS3, IFLS4

Note: Summary is for the pooled sample. Expenditures are adjusted for Consumer Price Index. 